\title{
Asset-price boom-bust cycles and credit: what is the scope of macro-prudential regulation?*
}

\author{
Vladimir Borgy ${ }^{\dagger}$ \\ Laurent Clerc ${ }^{\ddagger}$ \\ Jean-Paul Renne ${ }^{\S}$ \\ Banque de France \\ Banque de France \\ Banque de France
}

December 28, 2009

\footnotetext{
${ }^{*}$ We are very grateful to Béatrice Saes-Escorbiac and Aurélie Touchais for excellent research assistance. The views expressed in this paper do not necessarily reflect those of the Banque de France. We thank participants at the conference "The Macroeconomics of Housing Markets" (held in Paris on 3-4 December 2009) and at the ECB expert meeting on "Tools for detecting asset-price imbalances, the role of money and credit and the impact on consumer-price inflation" (held at Frankfurt on 15 December 2009). In particular, we thank our discussants Timo Wollmershäuser, Giovanni Ferri and Nicola Doyle for helpful comments. We are also grateful to the BIS for having kindly provided us with asset-price data.

†e-mail: vladimir.borgy@banque-france.fr

${ }^{\ddagger}$ corresponding author: Banque de France, DGEI-DEMFI; 31 rue Croix des Petits Champs, 75049 Paris cedex 01; e-mail: laurent.clerc2@banque-france.fr.

$\S$ e-mail: jean-paul.renne@banque-france.fr
} 


\begin{abstract}
Over the recent months, several initiatives have taken place to develop macro-prudential regulation in order to prevent systemic risk and the built-up of financial imbalances. Crucial to the success of such policy is the ability of the macro-prudential authority to identify in due time such imbalances, generally featured by asset-price boom-bust cycles. In this paper, we investigate the possibility of detecting asset-price booms according to alternative identification strategies and assess their robustness. We infer the probability that an asset-price boom turns into an asset-price bust. In addition, we try to disentangle costless or low-cost from costly asset-price booms. We find some evidence that house price booms are more likely to turn into costly recession than stock price booms. Resorting both to a non-parametric approach and a discretechoice (logit) model, we analyze the ability of a set of indicators to robustly explain costly asset-price booms. According to our results, real long-term interest rates, total investment, real credit and real stock prices tend to increase the probability of a costly housing-price boom, whereas real GDP and house prices tend to increase the probability of a costly stock-price boom. Regarding the latter, credit variables tend to play a less convincing role. From this perspective, we specify the scope of macro-prudential regulation as a set of tools aiming at avoiding "costly" asset-price booms. In doing so, we try both to make the case for state-contingent macro-prudential regulations and to set out clear delineation between monetary and financial stability objectives.
\end{abstract}

Keywords: Early Warning Indicators, Discrete-Choice Model, Asset Price Booms and Busts, Macroprudential Regulation, Leaning Against the Wind Policies

JEL Classification: E37; E44; E51.

\title{
Résumé
}

Comme suite à la crise financière, de nombreuses initiatives préconisant la mise en place de régulations macro-prudentielles visant à prévenir les risques systémiques et l'accumulation de déséquilibres financiers se sont fait entendre. Toutefois, la pertinence de ces propositions est conditionnelle à la capacité du régulateur macro-prudentiel, quel qu'il soit, à identifier, en temps réel, ces déséquilibres financiers qui sont généralement associés à des épisodes de boom et de krach de prix d'actifs. Dans cet article, nous étudions la possibilité d'identifier, de façon robuste, ces épisodes de booms et de krachs. Pour différentes méthodes de détection usuellement utilisées dans la littérature et pour différentes classes d'actifs (immobilier et actions), nous cherchons à évaluer la probabilité qu'un boom soit suivi d'un krach. Nous distinguons en outre des booms "coûteux" -en termes d'activité économique- de booms non coûteux (ou peu coûteux). Notre analyse suggère que les booms relatifs aux prix immobiliers sont plus faciles à identifier et qu'ils sont souvent suivis de krachs que les booms sur les actions. De plus, en se fondant sur une méthode nonparamétrique ainsi que sur l'estimation de modèles à choix discrets (logit), nous mettons en évidence le lien entre différents indicateurs macroéconomiques et l'occurrence de booms coûteux. Nos résultats suggèrent ainsi que les taux d'intérêt réels à long terme, l'investissement total, le crédit exprimé en termes réels ainsi que les prix des actions ont tendance à augmenter la probabilité qu'un boom de prix de l'immobilier soit coûteux, tandis qu'un écart du PIB réel à sa tendance de long-terme et les prix de l'immobilier accroissent celle qu'un boom boursier soit coûteux. Dans ce dernier cas, le rôle joué par les variables de crédit n'est pas clairement identifié. Globalement, nos résultats indiquent que la régulation macro-prudentielle devrait viser la prévention des booms coûteux. Nous abordons finalement les enjeux liés (a) à la mise en place de politiques macro-prudentielles contingentes et (b) à l'articulation entre objectifs de stabilité financière et de politique monétaire.

Mots clés: Indicateurs avancés, modèles de choix discrets, booms et krachs de prix d'actifs, régulation macro-prudentielle, politique de type "leaning against the wind"

Codes JEL: E37; E44; E51. 


\section{Introduction}

The recent financial crisis has triggered an impressive amount of policy initiatives and recommendations. Most of these proposals aim at developing macro-prudential regulations intended to address both pro-cyclicality and systemic risks in financial systems. An even more challenging objective is sometimes assigned to macro-prudential policies: avoiding asset-price bubbles (see Landau, 2009 for example).

Indeed, there are compelling evidence that the current financial crisis is the consequence of the bust of an housing-price bubble that took place in the US and spread out to most developed countries. The possible factors that have contributed to the built-up of this housing bubble are: a context of financial deregulation; a wave of financial innovations in the securitization process; bad incentives in the financial industry; regulatory arbitrage; too lax internal and external controls, in particular from supervisors only focused on individual institutions and missing systemic linkages; and eventually too accommodative monetary policies.

There is an open debate on whether central banks should go further to prevent the built-up of financial imbalances and factor in asset prices in their reaction function or in their definition of price stability. However, the consensus is that the interest rate is too blunt an instrument to reach this goal. But this objective could be achieved through macro-prudential policies by which competent authorities may finally be able to "lean against the wind." Therefore, the current discussions focus on the scope of macro-prudential regulation. A large consensus seems to emerge on its main instruments, which may be inter alia devoted to: tightening capital requirements; limiting credit expansion; introducing both liquidity and leverage ratios; controlling the degree of maturity transformation... According to most of these proposals, the preferred approach seems to mostly rely on a set of instrument rules functioning basically as automatic stabilizers.

In this paper, we argue that discretionary interventions from macro-prudential authorities should not be disregarded or, put another way, that there may be a case for state-contingent actions. In doing that, we try to set out delineation between monetary and financial stability objectives.

Our main concerns stem from the following considerations:

- First, credit expansions and even credit booms are not necessarily costly as implicitly assumed by most of the current discussions. Depending on identification procedures, there is evidence in the literature that credit cycles are asymmetric and that credit expansions do not systematically lead to busts. Therefore, macro-prudential rules should not limit credit developments per se but only address "bad booms", i.e. only those which are likely to turn into "costly" busts or severe economic contractions;

- Second, all assets are not alike: stocks behave differently than housing; their determinants 
are different, in particular regarding their link with credit developments; Some may be determined by global factors while others mostly stem from local ones;

- Third, suggested macro-prudential tools mostly apply to traditional monetary and financial institutions' balance sheets: they do not directly address off-balance sheet exposures nor the fact that an increasing part of domestic credit is generated outside the banking system. As argued by Adrian and Shin (2008), one should also consider investment banks' balance sheets;

- Finally, macro-prudential tools are more likely to address housing-price bubbles or booms than stock-price or other assets' misalignments as housing investment is mostly financed by banks.

The paper attempts to answer the following questions: is it possible to detect, in a robust way, asset-price booms? What is the probability that an asset-price boom turns into an asset-price bust? Is it possible to disentangle "good" -that is to say costless or low-cost booms- from "bad" -i.e. costly- asset-price booms? What are the main determinants of costly asset-price booms and do they differ from those explaining costless or low-cost asset-price booms? What is the scope of macro-prudential regulation and is there a case for state-contingent policies? If central banks are involved in macro-prudential supervision, can we set out clear delineation between monetary and financial stability objectives?

The rest of the paper is organized as follows. Section 2 provides an overview of the identification methods used in the literature and assesses their main merits and drawbacks. In section 3, we implement some of these methods to identify "costly asset-price booms" and assess the extent to which the results are consistent across methods. These episodes are identified using quarterly real private property and equity prices for 18 OECD countries, between 1970 and 2008, provided by the Bank of International Settlements (BIS). In section 4, we implement non-parametric tests to disentangle, amongst the set of "usual suspects", the variables which are more suited to explain costly booms with respect to costless or low-cost ones. We develop a "performance indicator" which helps us to detect the best indicator variables that are robust to the identification methods. Section 5 provides additional information based on a discrete-choice (logit) model. Section 6 draws policy conclusions.

\section{A quick overview of the methodologies used to detect asset-price booms and busts}

Bubbles are hard to detect. Furthermore, people disagree on their exact definition. ${ }^{1}$ To overcome these difficulties, the literature has rather focused on asset-price "booms" and "busts". However,

\footnotetext{
${ }^{1}$ See Gürkaynak (2008) for a recent survey on econometric tests of asset price bubbles.
} 
the question of whether a boom involves a bubble takes a new dimension at the current juncture. As one principal objective of macro-prudential regulation is to avoid bubbles, designing tools to address asset and credit bubbles based on indicators measuring asset and credit booms and busts may bear some costs from a welfare point of view. In addition, as credit and asset-price cycles are asymmetric and as busts are relatively rare and extreme events, setting automatic rules based on asset-price developments or credit expansions may have a cost in terms of foregone economic growth. ${ }^{2}$ These costs have to be accounted for when setting these new macro-prudential regulations.

Several recent papers have developed methodologies in order to identify asset-price booms and busts. The most recent papers try to disentangle more explicitly "costly" asset-price booms (as Alessi and Detken, 2009) or "bad" booms (as Barajas et al., 2008) as those which are more likely to result in a severe recession. Our contribution is in line with these recent approaches.

The general idea of the methodologies implemented in the literature is to identify periods in which the value of an asset price exceeds a pre-determined threshold. The computation of the threshold could be based on deviations from a trend series. Several parameters have to be specified in order to identify relevant episodes: the choice of the filtering procedure, the smoothing parameters used in such procedure, the level of the threshold values, whether filters have to be computed in real time or not and so on and so forth.

There is no commonly accepted methodology concerning the proper way to identify asset-price boom/bust episodes. For this reason, several methodologies (or variants) have been developed in the literature.

For instance, Bordo and Jeanne (2002) rely on a threshold based on the moving average of the year-on-year dynamics of asset prices. This procedure was implemented recently by Fatas et al. (2009) and Barajas et al. (2008). Based on such methodologies, there is evidence that asset-price booms are not systematically followed by busts but only for half of them and that housing booms are more likely to turn into a bust than stock-price booms.

Mendoza and Terrones (2008) applied a similar method to credit booms identification. Furthermore they discussed the implications of using a recursive trend versus a conventional trend. Their conclusions are broadly in line with the previous ones.

Agnello and Schuknecht (2009) develop another method (referred to as the "triangular method") based on the detection of peaks and troughs as Jaeger and Schuknecht (2007) or Harding and Pagan (2002). Compared to the previous method, this methodology leads to identifying episodes of boom and bust that do cover larger part of the sample (from one trough to the next peak concerning a boom).

In many cases, trends are estimated using a Hodrick-Prescott filter. Alessi and Detkens (2009)

\footnotetext{
${ }^{2}$ This is even without mentioning that financial crises may have on average a positive impact of economic growth (see Rancière et al., 2008). The rationale behind this paradoxical result is that weak financial institutions may lead to severe financial constraints and low growth.
} 
apply such method on 'real time' data, i.e. by only accounting for data known at a given period. The standard deviation, which is used to determine whether deviations from trend are statistically significant, is also computed recursively. As in Mendoza and Terrones (2008), this is done so as to allow country / path dependent patterns.

We first apply all these methods or a variant on a similar time series to assess the extent to which they deliver consistent results regarding the identification of boom-bust episodes and their main features.

\subsection{Hodrick-Prescott (HP) method}

This method consists in extracting a trend from the considered series (housing-price or stock-price indices) using the HP filter. Boom episodes (respectively bust episodes) are defined as periods during which the gap is larger than $\delta$ times its standard deviation (respectively lower than $-\delta$ times).

As an illustration, in Figure 1, booms and busts episodes are selected with respect to a gap larger than one standard deviation.

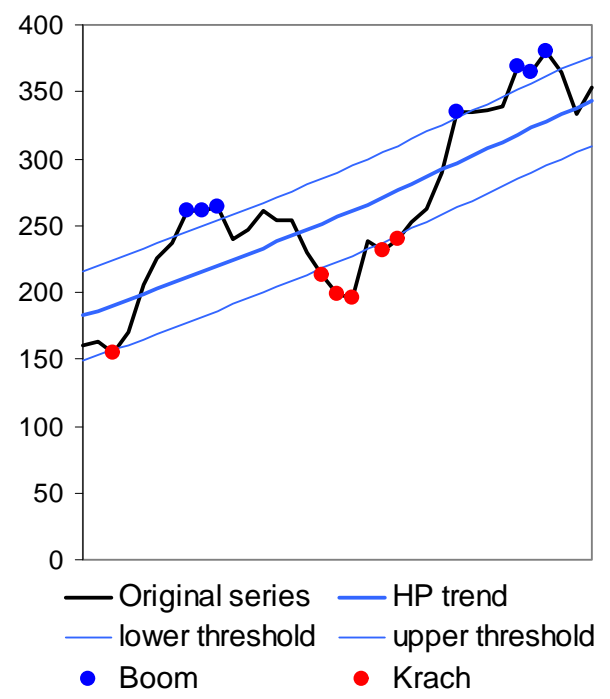

Figure 1: Hodrick-Prescott method

On the one hand, this method benefits from simplicity in terms of comprehension and easiness of use. On the other hand, it tends to detect relatively short-lived episodes. The identification procedure also depends upon the choice made regarding the duration of an episode. Some papers define an episode as a set of significant and consecutive deviations from the trend whereas others consider that two events occurring within a predefined period (say within a year) belongs to the same episode. In the above example, some will detect three booms and busts episodes whereas others would only see two booms and two busts. Besides, since optima are within the detected 
periods, the latter generally include the beginning of the next phase. Finally, this method is subject to end-of-sample bias associated with the HP filter. Papers by Goodhart and Hofmann (2008), Socorro Gochoco-Bautista (2008) or Cecchetti (2006) carry out similar methodology.

\subsection{Extended Hodrick-Prescott (EHP) method}

This method is based on the previous one (HP method) and is aimed at circumventing some of its drawbacks.

First, instead of keeping the entire period (denoted with $P$ ) for which the gap is above (respectively below) the threshold, the quarters that follow the maximum (respectively the minimum) of the gap on period $P$ are removed from the boom (respectively the bust) period.

Second, in order not to capture only the end of the episode (boom or bust), the periods are extended by adding $N$ quarters before the date at which the series breach the pre-determined threshold (however, the quarters are not added if these are already part of the precedent episode).

\subsection{Recursive Hodrick-Prescott (RHP) method}

This method differs from the HP method with respect to the use of the Hodrick Prescott filter, which is recursive in that case. Specifically, for each period $t_{1}$, one computes the HP-filtered series over the sample $\left[t_{0}, t_{1}\right]$. The last value of the obtained filtered series (corresponding to period $t_{1}$ ) is allotted to the recursive-HP-filtered series (for period $t_{1}$ ). As in the previous methods, boom and bust episodes are detected when the gap between the price series and the recursive-HP-filtered series is above or below a given threshold. The threshold can either be constant over the sample or be recursive (based on the standard deviation of the recursive gaps that are computed for each new period).

This method tends to detect episodes that are longer than in the HP-method case. In addition, as suggested by Figures 1 and 2, the episodes are detected earlier. This can be accounted for by the fact that -for the same smoothing parameter of the HP filter- the recursive-HP filter tend to be more pro-cyclical than the HP filter. As a consequence, the price series tends to cross the filtered series earlier in the recursive-HP case. To the extent that the recursive-HP filter is one-sided, this filter can be seen as a real-time one, which, depending on its use, may be seen as an advantage (if one wants to develop a method that is aimed at forecasting) or a drawback (if one is concerned with an ex post analysis that requires the largest available information). Papers by Alessi and Detken (2009), Adalid and Detken (2007) and Detken and Smets (2004) rely on such a methodology.

When implemented in real time, as in the case of Alessi and Detken (2009), this method tends to identify a lot of episodes at the beginning of the sample, due to the fact that the real time standard deviation is relatively small. In addition, for volatile time series, end-of-sample bias may lead to situations where an episode initially identified as a boom in real time turns out to be either 


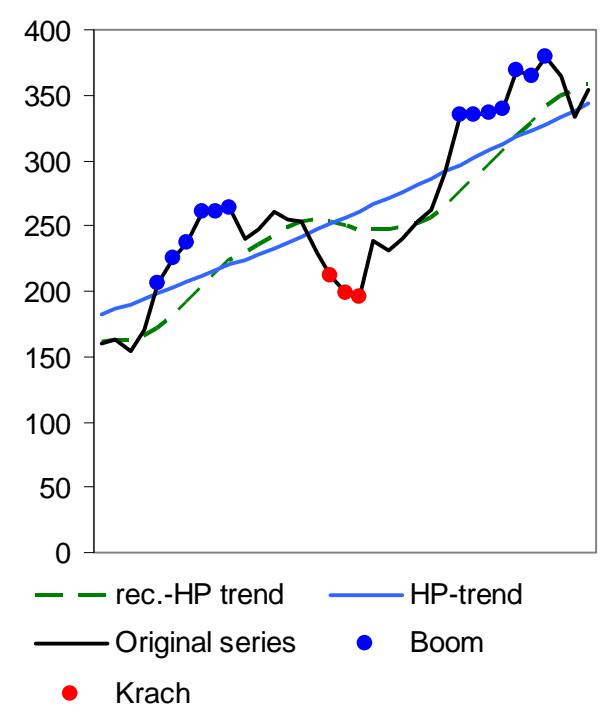

Figure 2: Recursive HP method

normal or even corresponds to a bust later on. As a result, this may bias signal-to-noise ratios which are key in the signalling literature.

\subsection{Band-pass filter (BP) method}

In this method, the gap is obtained by applying the Christiano-Fitzgerald band-pass filter to the -housing or stock- price series. To the extent that high frequencies are removed from it, the resulting gap is smoother, which makes it possible to clearly distinguish peaks and troughs.

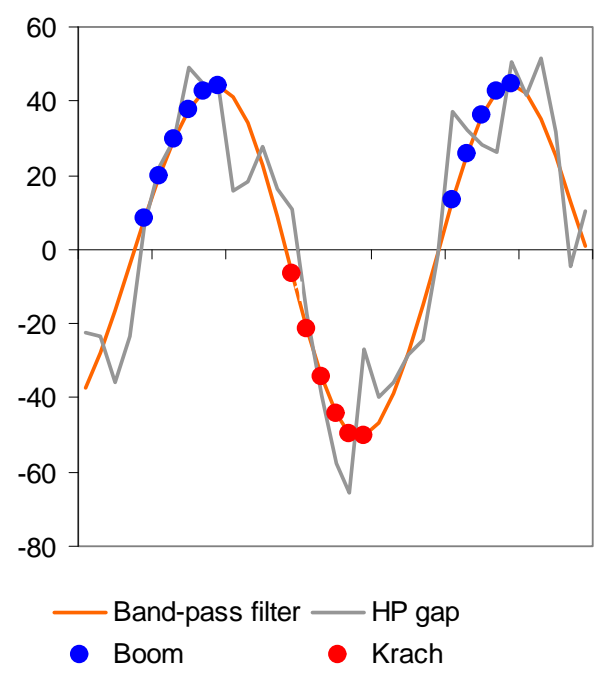

Figure 3: Band-Pass filter method

Amongst the gap optima -that are defined as maxima or minima over a given window of $W$ 
quarters-, only those that are sufficiently far from the zero line (the threshold being expressed as a multiple of the gap standard deviation) are retained.

Having identified these optima, the boom and bust episodes are defined in the following manner: the booms (respectively the busts) are the longest possible periods that are bounded by 0 on the left and a gap maximum (respectively a gap minimum) on the right; in addition, the gap is never negative (respectively positive) over the period.

The use of a band-pass filter that excludes high-frequency variability makes it easier to detect optima (see Figure 3), which may be seen as a way of using peaks and trough detection as in Agnello and Schuknecht (2009) at the quarterly frequency (while they use yearly data). It has to be noted that this method rules out the possibility of having contiguous booms and busts (unless there is a dramatic fall in the gap following a peak).

\subsection{Moving Average (MA) method}

In that case, one computes the moving average (including $M$ lags) of the year-on-year growth in the considered series (housing or stock prices). Those periods for which the mobile average is larger (respectively lower) than a threshold are identified as boom periods (respectively as bust periods).

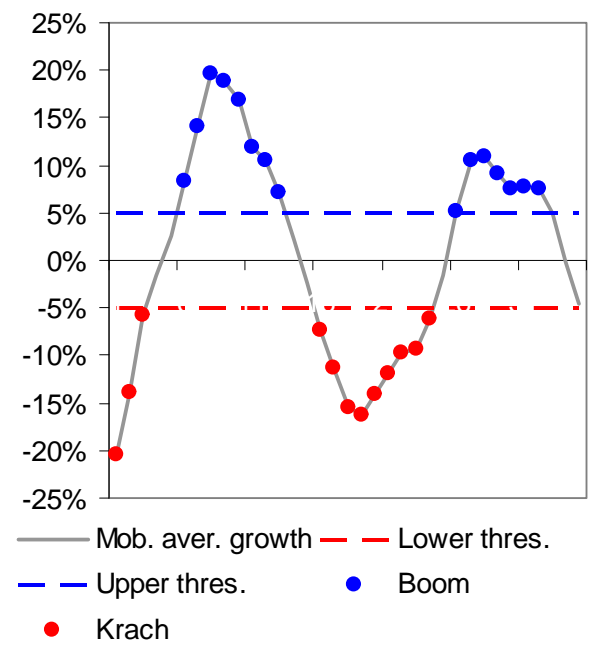

Figure 4: Moving-average method

This method is a real-time one in the sense that the diagnostic in period $t$ only depends on information that is known in $t$, which, as mentioned above, (in the recursive-HP case), can be either seen as an advantage or a drawback of the method, depending on its use. Contrary to previous ones, the MA method may detect a boom episode (respectively a bust episode) even in a context where the price series is below (respectively above) its trend. This potential pitfall may be avoided by conditioning the detection to the position in the cycle (which would naturally require the computation of a cycle indicator). Bordo and Jeanne (2002), Fatas et al. (2009) and 
Barajas et al. (2008) rely on that method to select their episodes. Gerdesmeier, Reimers and Roffia (2009) implement similar method -however based on a recursive average- to an asset-price composite indicator which incorporates developments in both stock and house price and focus on bust episodes.

Overall, as will be illustrated hereinafter, the different methods seem to deliver quantitatively similar but qualitatively different results: they spot more or less the same episodes but their duration and main features (such as the degree of asymmetry for instance) differ significantly.

\section{Identification of costly asset-price booms}

In this section, we implement these different methodologies on real housing and stock-price quarterly indices, from 1970Q1 to 2008Q3, collected on a set of 18 OECD countries: Australia, Belgium, Canada, Denmark, Finland, France, Germany, Ireland, Italy, Japan, the Netherlands, NewZealand, Norway, Spain, Sweden, Switzerland, the United-States, the United-Kingdom. Real housing prices have been provided by the BIS. The data sources for stock prices are IMF's International Financial Statistics and Thomson Financial - Datastream.

The different methods are implemented mechanically in order to define asset-price booms and busts episodes. An asset-price boom (bust) is defined as:

- Using the moving average method: a period when the 8-quarter trailing moving average of the annual growth rate of the considered asset price exceeds (falls below) a given threshold, i.e. when: $1 / 8 \sum_{i=0}^{7} g_{t-i}>x$, where $g$ is the growth rate of the asset price and $x$ the threshold. In this exercise, $x$ is set equal to $5 \%$ ( $-5 \%$ for a bust) for housing prices and $15 \%(-15 \%)$ for stock prices to account for the higher volatility of the latter prices. ${ }^{3}$ The duration of an episode is measured as the amount of time the 8-quarter moving average of the growth rate of the asset price exceeds (falls below) the threshold. When the above condition holds, the periods $t-7$ through $t$ are labeled as a boom (bust). Consequently, the minimum duration of all episodes is of two years. This is consistent with Fatas et al. (2009) though their moving average is computed over 4 quarters only.

- Using the recursive HP filter: a period when asset-price deviations from trend is over $+/$ 1.3 times the standard deviation. This threshold is equal to the one considered in Bordo and Jeanne (2002). The trend is computed using a one-sided HP filter with a smoothing coefficient of 100.000 as in Alessi and Detken (2009).

- Using the "extended" HP filter: as in the previous method, regarding the parameters, but arbitrarily including the 12 quarters ahead of each episode.

\footnotetext{
${ }^{3}$ It is also chosen so as to be consistent with other methods.
} 
- Using the band-pass filter: a period when the Christiano-Fitzergerald band-pass filter exceeds (falls below) zero by more than one standard deviation. The gap optima are defined as maxima or minima over a given window of 5 quarters as in Agnello and Schuknecht (2009) who implement a peak-to-trough approach. The filter is calibrated so as to filter out cycles below 2 years and above 30 years.

Then, we differentiate between the identified asset-price booms those which have a significantly negative impact and those which have a mild or even negligible impact on the economic activity. We use the same definition as in Alessi and Detken (2009), that is to say that we define a "costly" asset-price boom as a boom which is followed by a three-year period in which overall real GDP growth has been at least three percentage points lower than potential growth. Put another way, a costly boom results in a cumulated loss amounting to at least three percentage points of potential output in the three-year period following the peak in the asset price or a widening of the output gap by 3 percentage points. In order to identify costly and low-cost asset-price boom for the recent years, we complete the GDP data with forecasts published by the OECD (Economic Outlook, July 2009).

Figures 9 to 16 in the appendix depict periods in which the asset-price indices breach the boom and bust thresholds for all the above mentioned methods. Costly boom quarters are depicted in black, low cost booms are grey, unclassified booms are light blue and asset-price busts are red. The main features of the identified episodes are summarized in Table 1.

A first striking result stemming from Table 1 is that there are huge differences not only across methodologies but also across assets. It is also likely that changes in the parameter and threshold values may lead to dramatic changes in the set of identified episodes. Consequently, identifying asset-price booms is certainly easier than identifying asset-price bubbles, but it is not necessarily as robust and as easy as usually expected. The moving average and the "extended" HP filter methods on the one hand, the recursive HP and the Band-pass filters on the other, tend to display close results. The fact that the identification method has a huge and different impact across the asset classes also probably makes the case against aggregating several asset prices into a single index.

Second, the number of episodes varies a lot depending on the method implemented, with a greater variance regarding stock prices. In our sample, we identify between 70 and 40 booms and busts episodes for stock prices, 20 to 40 out of which being costly booms, and between 50 and 30 housing-price booms and busts, 20 to 30 being qualified as costly episodes. Therefore, stock-price boom and bust episodes tend to be more frequent that house-price ones. They also tend to be relatively shorter. However, "costly" asset-price booms are relatively more frequent for housing than for stock prices, and they are relatively more persistent. 
Regarding the robustness of the identification methods, one can check whether methods, confronted two-by-two, display coherent and synchronized results. Table 2 displays the percentage of periods in which two alternative methods give a similar diagnostic or signal regarding the state of asset-price developments (i.e. whether there is a booming phase or a busting phase).

\begin{tabular}{|c|c|c|c|c|}
\hline & \multicolumn{2}{|c|}{ Stock prices } & \multicolumn{2}{|c|}{ Housing prices } \\
\hline & \multicolumn{4}{|c|}{ Moving-Average-based detection method* } \\
\hline & $\mathrm{Nb}$ of episodes & Avg length & $\mathrm{Nb}$ of episodes & Avg length \\
\hline Booms & 55 & 18 & 51 & 19 \\
\hline costly & 26 & 17 & 25 & 19 \\
\hline costless/low-cost & 29 & 20 & 22 & 18 \\
\hline \multirow[t]{3}{*}{ Busts } & 56 & 13 & 40 & 17 \\
\hline & \multicolumn{4}{|c|}{ Recursive-HP-based detection method } \\
\hline & $\mathrm{Nb}$ of episodes & Avg length & $\mathrm{Nb}$ of episodes & Avg length \\
\hline Booms & 58 & 9 & 45 & 9 \\
\hline costly & 18 & 9 & 23 & 10 \\
\hline costless/low-cost & 40 & 8 & 22 & 8 \\
\hline \multirow[t]{3}{*}{ Busts } & 39 & 5 & 40 & 11 \\
\hline & \multicolumn{4}{|c|}{ Extended-HP-based detection method } \\
\hline & $\mathrm{Nb}$ of episodes & Avg length & $\mathrm{Nb}$ of episodes & Avg length \\
\hline Booms & 60 & 16 & 37 & 16 \\
\hline costly & 29 & 16 & 23 & 15 \\
\hline costless/low-cost & 31 & 16 & 14 & 18 \\
\hline \multirow[t]{3}{*}{ Busts } & 66 & 14 & 34 & 16 \\
\hline & \multicolumn{4}{|c|}{ Band-pass-filter-based detection method } \\
\hline & $\mathrm{Nb}$ of episodes & Avg length & $\mathrm{Nb}$ of episodes & Avg length \\
\hline Booms & 70 & 10 & 42 & 14 \\
\hline costly & 41 & 11 & 33 & 14 \\
\hline costless/low-cost & 29 & 10 & 9 & 14 \\
\hline Busts & 50 & 14 & 33 & 14 \\
\hline
\end{tabular}

Table 1: Summary statistics on house and stock price booms and busts. * Implementing this method, 4 additional booms were identified but could not be qualified

\begin{tabular}{|c|c|c|c|}
\hline & \multicolumn{3}{|c|}{ Stock prices } \\
\hline & Moving Average & Recursive HP Filter & Extended HP Filter \\
\hline Moving Average & - & - & - \\
\hline Recursive HP Filter & $55 \%$ & - & - \\
\hline Extended HP Filter & $60 \%$ & $49 \%$ & - \\
\hline \multirow[t]{3}{*}{ Band-pass filter } & $45 \%$ & $53 \%$ & $63 \%$ \\
\hline & \multicolumn{3}{|c|}{ Housing prices } \\
\hline & Moving Average & Recursive HP Filter & Extended HP Filter \\
\hline Moving Average & - & - & - \\
\hline Recursive HP Filter & $59 \%$ & - & - \\
\hline Extended HP Filter & $53 \%$ & $64 \%$ & - \\
\hline Band-pass filter & $53 \%$ & $64 \%$ & $75 \%$ \\
\hline
\end{tabular}

Table 2: Method synchronization 
It follows, from Table 2, that housing-price booms and busts are more consistently identified across methodologies than stock-price episodes. In addition, Table 2 suggests that the extendedHP and the band-pass filters display the closest results ( $75 \%$ of coherent signals for housing prices and slightly less for stock prices, with $63 \%$ ).

Another perspective on the episode-classification results is provided in Figures 5 and 6, which display "diffusion indices". These indices are obtained, for a given method and at a given date, by summing up across our set of 18 OECD countries an indicator variable of the state of the assetprice development. This indicator variable takes the value 1 when the asset price is in a booming phase, zero when the phase is unclassified, and -1 when it is a busting period. It corresponds to a crude measure of correlation in asset prices in the sense that if boom-bust cycles are local and/or uncorrelated phenomena, this summation should lead to a small number with respect to the total number of countries in the sample, a boom in a place being eventually compensated by a bust in another.
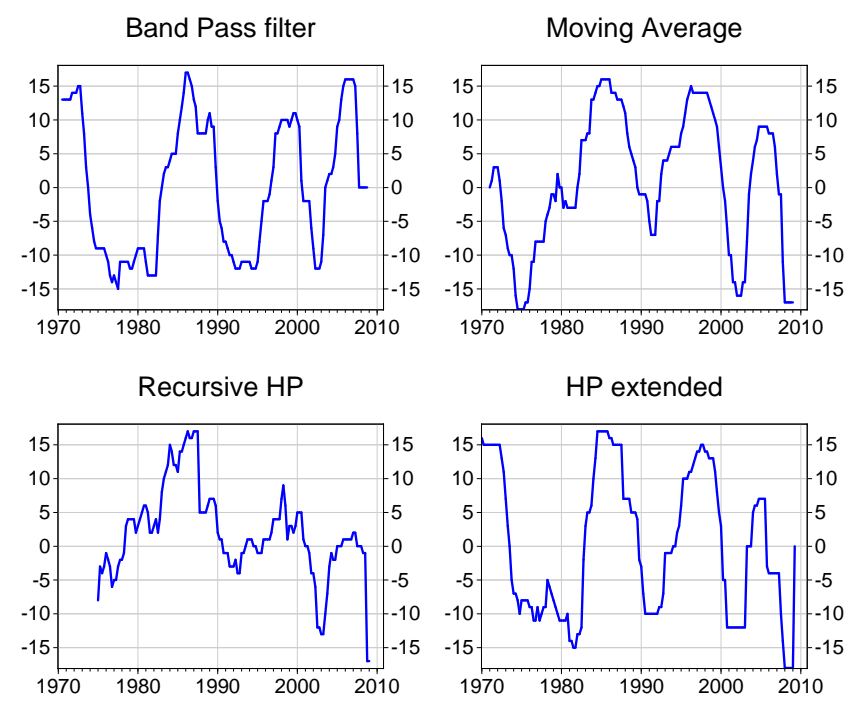

Figure 5: Diffusion indices: Stock prices

Depending on the method, one can identify four major waves of stock-price booms (which peaked around 1972, 1987, 1998/2000, 2007) and three of house-price booms (peak: 1979, 1989 and 2006) since 1970. Confronting these dates with Figures 9 to 16 in the appendix tend to show that almost all these waves were classified as costly booms. The second information stemming from these diffusion indices relates to the number of countries experiencing a boom or a bust episode simultaneously. As before, the results are highly dependent upon the method implemented 
Band Pass filter

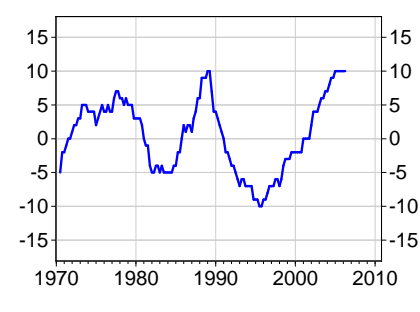

Recursive HP

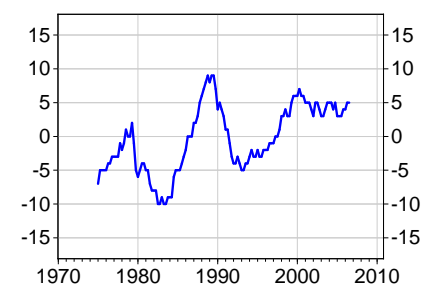

Moving Average

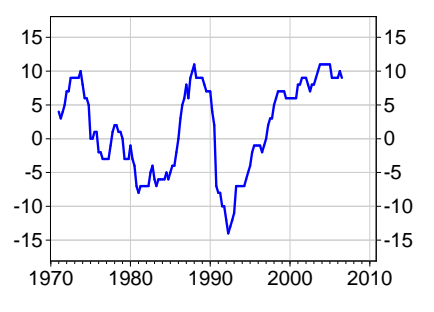

HP extended

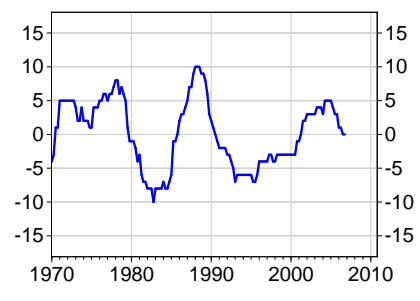

Figure 6: Diffusion indices: House prices

to select episodes and the class of asset considered. The main result is however that stock-price boom episodes tend to be simultaneous across our sample of countries as around 15 to 16 out of 18 countries are in general simultaneously either in a boom or in a bust. By contrast, for housing prices, the number of countries experiencing simultaneously a boom or a bust being rather limited (between 5 and 10 out of 18). This would tend to show that stock prices are more likely to be influenced by global or common factors than house prices.

In addition, we can consider the proportion of costly booms amongst all asset booms. This is shown in Figures 7 and 8. These Figures strinkingly illustrate the fact that the great bulk of house-price booms belongs to the category "costly booms" whereas it is the case for only a small portion of stock-price booms, but in the last cycle.

Based on our results, we are now in position to measure the probability an asset-price boom turns into an asset-price bust. Specifically, we consider that a boom turns into a bust if a bust begins in the two years following the end of this boom. The results are displayed in Table 3. 


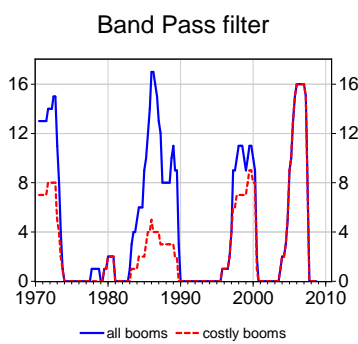

Recursive HP

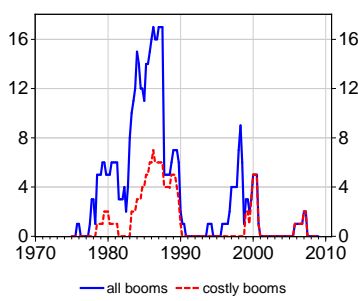

Moving Average

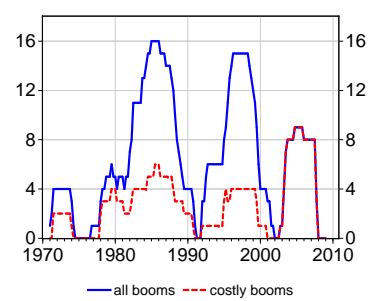

HP extended

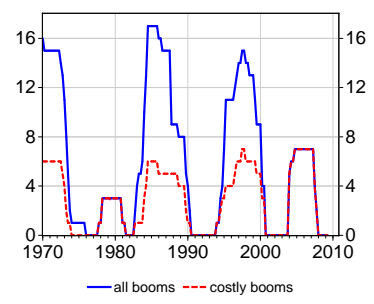

Figure 7: Number of costly booms: Stock prices
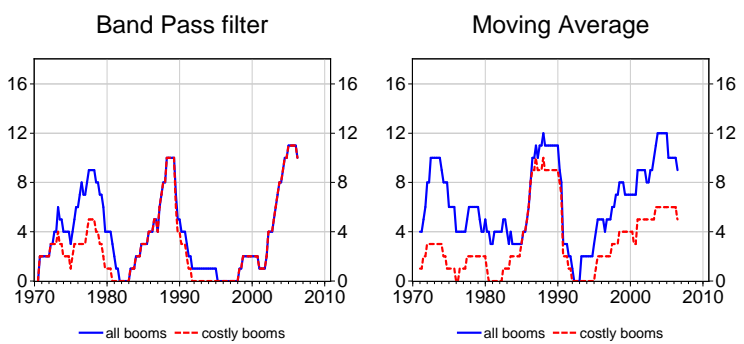

Recursive HP

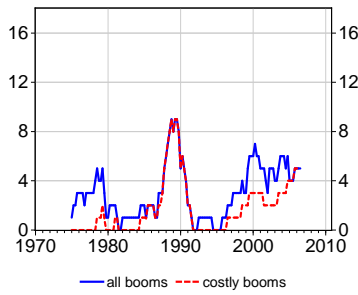

HP extended

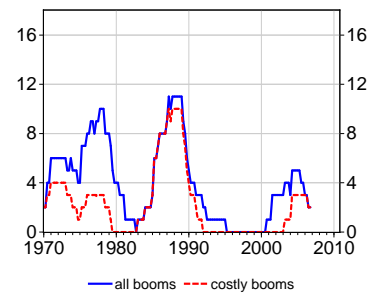

Figure 8: Number of costly booms: House prices 


\begin{tabular}{|c|c|c|}
\hline Probability that a boom is followed by a bust & STOCKS & HOUSING \\
\hline \multicolumn{3}{|l|}{ Moving Average } \\
\hline $\begin{array}{l}\text { whatever kind of boom } \\
\text { - if the boom is not costly } \\
\text { - if the boom is costly }\end{array}$ & $\begin{array}{l}70 \% \\
72 \% \\
65 \%\end{array}$ & $\begin{array}{l}67 \% \\
60 \% \\
74 \%\end{array}$ \\
\hline \multicolumn{3}{|l|}{ Recursive Hodrick Prescott filter } \\
\hline $\begin{array}{l}\text { whatever kind of boom } \\
\text { - if the boom is not costly } \\
\text { - if the boom is costly }\end{array}$ & $\begin{array}{c}9 \% \\
0 \\
31 \%\end{array}$ & $\begin{array}{l}23 \% \\
18 \% \\
28 \%\end{array}$ \\
\hline \multicolumn{3}{|l|}{ Extended Hodrick Prescott Filter } \\
\hline $\begin{array}{l}\text { whatever kind of boom } \\
\text { - if the boom is not costly } \\
\text { - if the boom is costly }\end{array}$ & $\begin{array}{l}57 \% \\
52 \% \\
64 \%\end{array}$ & $\begin{array}{l}47 \% \\
50 \% \\
45 \%\end{array}$ \\
\hline \multicolumn{3}{|l|}{ Band-pass filter } \\
\hline $\begin{array}{l}\text { whatever kind of boom } \\
\text { - if the boom is not costly } \\
\text { - if the boom is costly }\end{array}$ & $\begin{array}{l}67 \% \\
52 \% \\
84 \%\end{array}$ & $\begin{array}{l}35 \% \\
22 \% \\
41 \%\end{array}$ \\
\hline
\end{tabular}

Table 3: Probabilities that an asset price boom is followed by a bust (with respect to the detection method)

First, there is clear evidence that an asset-price boom is not systematically followed by an asset-price bust. Roughly speaking, it is broadly the case for about half of them. However, Table 3 displays huge differences across methods and assets. Based on these results, it is however difficult to establish that housing booms are more prone to price busts than stocks. This clearly depends upon the implemented method.

Second, there is a case to distinguish costly and non-costly booms as, irrespective the method and the asset class, a boom qualified as costly turns more systematically into a bust than a "noncostly" one. In this case, the probability is at least $40 \%$ and can be as high as $80 \%$. It follows also that an asset-price bust may have mild effects on the economy and may not necessarily require a policy response.

Finally, if one would like to identify costly asset price booms with the highest probability, he would have to resort to a specific method for each asset class, namely band-pass filter to identify costly stock price booms and moving-average in the case of house price booms.

Overall, it seems that designing systematic or mechanistic macro-prudential rules is not necessarily a panacea. These rules should therefore be designed in order to address and prevent costly asset-price booms only. Otherwise, they may bear some deadweight welfare losses and from this view point would neither be desirable nor justified.

The questions we are now confronted with are the following: are we able, amongst the set of usual early warning indicators, to distinguish those which will signal costly booms only? Are they 
different from those leading or signalling booms with mild or even without any consequences on the real economy? This is the scope of the next session.

\section{The determinants of costly booms: a non-parametric ap- proach}

\subsection{The "usual suspects"}

There is a long standing literature focusing on past asset market booms from which we can spot a set of relevant early warning indicators (see e.g Bordo and Wheelock, 2004 or Schularick and Taylor, 2009). The list is not exhaustive but usually contains:

- several macro-economic variables illustrative of a "regime" or "paradigm" shift ("new economy") such as: above-trend growth, below trend inflation, current account deterioration (capital flows), falling private sector savings;

- credit and monetary indicators such as: faster real money supply growth, M2-to-reserve expansion, above trend domestic credit, rising foreign reserves;

- and finally global factors such as: global commodity price collapse, global liquidity. One can add to this list very accommodative financing conditions featured by historically low interest rates.

Due to data availability and working on a set of 18 OECD countries from 1970 to 2008 on a quarterly basis, we restrict our attention to the 19 indicators listed in Table 4. Moreover, we consider up to 3 different transformations of these variables in addition to the data itself (deviation from an HP trend, deviation from a linear trend and annual growth rate or annual change) and up to 5 different lags (from contemporaneous to 4-quarter lagged observations). Therefore, we overall test the information content of 380 indicators. 


\begin{tabular}{l}
\hline \hline Housing prices \\
Stock prices \\
\hline Real GDP \\
\hline Residential investment \\
Residential-investment-to-GDP ratio \\
Investment \\
Total-investment-to-GDP ratio \\
\hline Credit (real) \\
Credit \\
Credit-to-GDP ratio \\
Money (real) \\
Money \\
Money-to-GDP ratio \\
\hline Nominal long-term rate \\
Nominal short-term rate \\
Real long-term rate \\
Real short-term rate \\
Spread \\
\hline Current-account-to-GDP ratio \\
\hline \hline
\end{tabular}

Table 4: List of indicator variables

Real GDP, Investment, Residential investment -both in level and as GDP ratios- aim at capturing the potential effects of real activity on asset markets' developments. In particular, we expect that buoyant real activity might fuel asset demand from the income or the expectations channels and be prone to asset-price booms.

Real credit variables tend to capture the "credit view", which states that the quantity of bank credit matters, above and beyond the level of bank money. Put another way, proponents of that view consider that the entire banks' balance sheet, leverage and composition may have macroeconomic implications. Propagation occurs through a financial accelerator mechanism (as in Bernanke and Blinder, 1988) or through collateral constraints (as in Bernanke, Gertler and Gilchrist, 1999). Recent research carried out at the ECB indeed shows that credit variables seem to be pretty good early warning indicators of asset-price busts (Gerdesmeier et al., 2009) or of costly asset-price booms (Alessi and Detken, 2009), thereby confirming earlier findings by Borio and Lowe (2002).

Monetary aggregates (we focus here on broad aggregates such as M3) intend to capture the "money view", which states that the level of money supply strongly influences output in the short term and as such might also feeds asset-price booms. It reflects the importance of aggregate liquidity in fuelling asset markets' development and emphasizes the role of aggregate banks liabilities (or funding liquidity) beyond the role of monetary and financial institutions in credit creation.

Current account variables intend both to capture the role of capital inflows and more generally of global imbalances in the formation and the developments of asset-price bubbles and to explain eventually the discrepancy between broad monetary aggregates and credit developments (corre- 
sponding to the external counterpart of broad monetary aggregates). There is indeed compelling evidence that capital flows might both explain inflationary pressures and asset-price booms as observed in Latin America in the 80s and 90s, in emerging Asia in the late 90s and have played a role in the builtup to the current crisis (on this last point, see IMF, 2009).

Interest rates (real, nominal and spread) reflect the behavior of central banks or monetary authorities. We use them to assess the extent to which historically low level of interest rates may be prone to asset-price bubbles. This stems from the fact that a lower level of interest rates tends first to increase the level of future expected dividends, in the case of stocks, or rents, in the case of housing, while at the same time decreasing the values of discount factors, thereby resulting in an increase in asset prices. In addition, it should be borne in mind that during an asset-price boom, one would expect that an interest rate increase may trigger a bust or signal a costly boom as it may exacerbate both adverse selection and moral hazard problems and increase defaults of overindebted households or firms.

Finally, we investigate the information content of housing prices to account for stock-price developments and vice-versa. This may eventually capture the impact or housing or financial wealth on other asset prices, resulting either from portfolio rebalancing or diversification.

\subsection{A non-parametric analysis}

A first assessment of the links between the above-mentioned variables and the occurrences of specific episodes, say boom (vs. no boom) or costly boom (vs. non-costly / low cost boom), is obtained by resorting to non-parametric tests. By definition, these tests are immune to specification errors. In addition, they do not require satisfying particular assumption regarding the distribution of the variables. The straightforwardness of their implementation makes it possible to quickly look for potentially relevant determinants of some episodes amongst a large set of variables. Indeed, the number of variables to test dramatically increases when different lags and transformations of the variable are considered in the analysis.

Intuitively, if one suspects a given variable to be a determinant of a kind of episode, say a boom, one should expect this variable to have different characteristics before and during the boom. As an illustration, Figure 17 in the appendix shows that while changes in credit-to-GDP ratios tend to be higher during costly housing booms and lower during housing busts, the evidence is weaker for stock prices. Besides, this result seems to be relatively robust across the different identification methods. The approach that is developed in the following is aimed both at testing the significance of such qualitative observations and at finding the relevant lags and transformations to apply to the set of potential determinants in the second approach (see section 5).

Our approach is based on an extensive use of the Kruskall-Wallis tests (see Sheshkin, 1997 and for some applications, see e.g. Musard-Gies, 2006 or Clare and Courtenay, 2001), whose null 
hypothesis is the equality of medians of different sets of observations. ${ }^{4}$ More generally, assume that a set of observations is split into two. If one subgroup tends to contain the higher observations, the KW test statistics is high and the null hypothesis of equal medians is rejected. Conversely, if the ranking of the observations is relatively even over the two subgroups, the test statistics is low and the null hypothesis is not rejected. This functioning of the KW test statistics is exploited in order to rank the potentially explicative variables. Our approach is also designed so as to accommodate our objective of finding variables whose relationship with given episodes is robust across the four detection methods: a single performance measure $p^{X}$-based on the computation of the KW test statistics for each of the four detection methods- is indeed attributed to each variable $X$, transformation and lag. More precisely, the sequencing of the approach is the following:

1. For each variable $X$, transformation $T$, lag $k$ and detection method $d$ :

(a) The observations of the -transformed and lagged- variables are ranked and divided in two subgroups -denoted by A and B-, depending on the type of episodes they correspond to.

(b) Based on this decomposition, the KW test statistic - denoted by $K W_{d, T, k}^{X}$ - is computed, as well as the medians $m_{d, T, k}^{A, X}$ and $m_{d, T, k}^{B, X}$ of the two subgroups. The relative position of the medians reflects the direction of the potential effect of the considered variable on the type of episode (for the considered lag, transformation and detection method).

2. For each variable, transformation and lag, if the direction of the effect is different across the four detection methods, a zero performance is attributed to this transformed-and-lagged variable $\left(p_{T, k}^{X}=0\right)$. Otherwise, the minimum of the four test statistics (corresponding to the four detection methods) is taken as the performance metrics for this transformed-and-lagged variable.

3. For each variable, one looks for the transformation and lag that results in the best performance metrics. ${ }^{5}$

Formally, steps 2 and 3 read

$$
p^{X}=\operatorname{Max}_{T, k} p_{T, k}^{X}
$$

where $p_{T, k}^{X}=\left\{\begin{array}{c}\text { if, } \forall d m_{d, T, k}^{A, X}>m_{d, T, k}^{B, X} \text { or } \forall d m_{d, T, k}^{A, X}<m_{d, T, k}^{B, X} \\ 0 \text { otherwise. }\end{array}\right.$ then $\operatorname{Min}_{d} K W_{d, T, k}^{X}$

\footnotetext{
${ }^{4}$ The test statistic is $K W=12 /(N(N+1)) \sum_{k}^{K} R_{k}^{2} / n_{k}-3(N+1)$ where $K$ is the number of groups, $n_{k}$ is the number of observations in group $k$, and $R_{k}=\sum_{i=1}^{n_{k}} r_{i, k}$ is the rank sum for group $k\left(r_{i, k}\right.$ being the rank of the $i^{t h}$ observation of group $k$ ) and $N$ is the total number of observations $\left(N=\sum_{i=1}^{K} n_{k}\right)$. Under the null hypothesis of equal medians, the $K W$ statistics is distributed $\chi^{2}(K-1)$. Specifically, in our case, $K$ is equal to 2 (boom vs. no-boom in a first analysis and costly-boom periods vs. non-costly-boom periods in a second one).

${ }^{5}$ As a result, steps 2 and 3 constitute a MaxMin approach: after having selected the smallest value of the KW statistics with respect to the detection method (for each variable, lag and transformation), we maximize with respect to the different lags and transformations.
} 
Since all the performance metrics $p^{X}$ originally were computations of KW test statistics following $\chi^{2}(1)$ distributions under the null hypothesis-, they can be compared to the associated critical values. Accordingly, a performance $p^{X}$ which lies below the $5 \%$ critical value of the KW test points to a weak relationship between this variable and the types of considered episodes. More precisely, if a variable falls in this category, it means either that for any lag and any transformation applied to it, (1) the detection methods never agree on the sign of the relationship or (2) there is at least one detection method for which the relationship was not statistically significant.

While Tables 5 and 6 are aimed at analyzing the potential determinants of booms for housing and stock prices respectively, Tables 7 and 8 present the results when looking for the determinants of the "costly" booms. In all these tables, the variables are ranked with respect to their performance metrics $p^{X}$.

Considering first housing-price booms versus the absence of boom, macroeconomic variables expressed as deviations from trend (Real GDP, Investment, Residential and total investment) tend to be the most relevant and robust across methods determinants with the expected positive signs, followed by the year-on-year growth rate of credit variables, which tend to dominate broad monetary aggregate indicators (see Table 5). Low nominal, rather than real, long-term interest rate also explain housing-price booms quite significantly but with a lag.

Stock price booms determinants tend to be dominated by rather different variables, in particular credit indicators but with unexpected negative signs (see Table 6). For instance, below trend credit would tend to signal or characterize stock-price booms. Looking at real variables, they also display counterintuitive results, but for investment. Low nominal interest rates tend to explain stock-price booms consistently with what was found earlier in the case of house prices. 


\begin{tabular}{lrrrr}
\hline \hline & Lag & Transformation & Performance & Direction \\
\hline \hline Housing prices & 0 & Annual growth & 488,1 & + \\
\hline Real GDP & 0 & Gap (HP trend) & 252,8 & + \\
Investment & 0 & Gap (HP trend) & 187,5 & + \\
Residential investment & 0 & Gap (HP trend) & 157,8 & + \\
Residential investment-to-GDP ratio & 0 & Gap (HP trend) & 133,5 & + \\
Total investment-to-GDP ratio & 0 & Gap (HP trend) & 96,5 & + \\
Credit (real) & 0 & Annual growth & 95,3 & + \\
Credit & 2 & Annual growth & 77,8 & + \\
Credit-to-GDP ratio & 1 & Annual growth & 67,5 & + \\
Current account-to-GDP ratio & 0 & Annual change & 57,3 & - \\
Money (real) & 0 & Gap (linear trend) & 50,1 & + \\
Nominal long-term rate & 4 & Gap (HP trend) & 36,5 & - \\
Money & 3 & Annual growth & 33,7 & + \\
Stock prices & 3 & Gap (HP trend) & 33,6 & + \\
Money-to-GDP ratio & 4 & Annual growth & 29,4 & + \\
Nominal short-term rate & 4 & Gap (HP trend) & 26,9 & - \\
Real long-term rate & 0 & No transf. & 8,2 & - \\
Real short-term rate & 4 & Gap (linear trend) & 6,8 & - \\
Spread & 4 & Gap (HP trend) & 5,4 & + \\
\hline \hline
\end{tabular}

Table 5: Non-parametric analysis of potential determinants of house price booms. Notes: The performance metrics is based on the Kruskall-Wallis test. Heuristically, the larger this metrics, the more dependent on the type of episodes (boom vs. non boom) the behavior of the considered variable; the last column indicates the direction of the relationship $(a+\operatorname{sign}$ means that the considered variable tends to have larger values during booms).

\begin{tabular}{lrrrr}
\hline \hline & Lag & Transformation & Performance & Direction \\
\hline \hline Stock prices & 0 & Annual growth & 520,6 & + \\
\hline Credit & 3 & Gap (HP trend) & 135,3 & - \\
Housing prices & 4 & Gap (HP trend) & 131,9 & - \\
Credit-to-GDP ratio & 1 & Gap (HP trend) & 124,7 & - \\
Real GDP & 4 & Gap (HP trend) & 118,4 & - \\
Money & 1 & Gap (HP trend) & 83,6 & - \\
Credit (real) & 4 & Gap (HP trend) & 80,0 & - \\
Investment & 0 & Annual growth & 71,6 & + \\
Money-to-GDP ratio & 0 & Gap (HP trend) & 67,2 & - \\
Nominal long-term rate & 3 & Annual change & 66,7 & - \\
Residential investment-to-GDP ratio & 0 & Annual growth & 54,7 & + \\
Real long-term rate & 4 & Gap (HP trend) & 44,4 & + \\
Money (real) & 4 & Gap (HP trend) & 36,0 & - \\
Residential investment & 4 & Gap (HP trend) & 28,0 & - \\
Current account-to-GDP ratio & 3 & Gap (HP trend) & 27,9 & + \\
Nominal short-term rate & 4 & Annual change & 22,9 & - \\
Spread & 3 & Gap (HP trend) & 16,0 & + \\
Total investment-to-GDP ratio & 4 & Gap (HP trend) & 9,3 & - \\
Real short-term rate & 4 & No transf. & 8,3 & + \\
\hline \hline
\end{tabular}

Table 6: Non-parametric analysis of potential determinants of stock price booms. Notes: see pervious Table. 


\begin{tabular}{lrrrr}
\hline \hline & Lag & Transformation & Performance & Direction \\
\hline \hline Real long-term rate & 4 & No transf. & 52,0 & + \\
Real short-term rate & 4 & No transf. & 46,0 & + \\
Stock prices & 0 & Gap (HP trend) & 33,8 & + \\
Residential investment-to-GDP ratio & 4 & Annual growth & 30,7 & + \\
Investment & 1 & Annual growth & 24,8 & + \\
Total investment-to-GDP ratio & 3 & Gap (HP trend) & 20,8 & + \\
Credit (real) & 1 & Annual growth & 19,9 & + \\
Money (real) & 0 & Annual growth & 9,6 & + \\
Residential investment & 3 & Gap (HP trend) & 9,1 & + \\
Credit-to-GDP ratio & 2 & Annual growth & 6,6 & + \\
Money-to-GDP ratio & 1 & Annual growth & 5,7 & + \\
Housing prices & 0 & Annual growth & 2,4 & + \\
Real GDP & 0 & Annual growth & 1,5 & + \\
Spread & 0 & Annual change & 1,0 & - \\
Nominal long-term rate & 4 & Gap (linear trend) & 0,2 & + \\
Credit & 4 & Annual growth & 0,1 & + \\
Current account-to-GDP ratio & 0 & Gap (linear trend) & 0,0 & - \\
\hline \hline
\end{tabular}

Table 7: Non-parametric analysis of potential determinants of the type of house price booms (costly vs. costless or low-cost). Notes: The performance metrics is based on the Kruskall Wallis test. Heuristically, the larger this metrics, the more dependent on the type of episodes (costly boom vs. non-costly boom) the behavior of the considered variable; the last column indicates the direction of the relationship $(\mathrm{a}+$ sign means that the considered variable tends to have larger values during costly booms).

\begin{tabular}{lrrrr}
\hline \hline & Lag & Transformation & Performance & Direction \\
\hline \hline Real GDP & 0 & Gap (HP trend) & 44,4 & + \\
Housing prices & 3 & Annual growth & 34,2 & + \\
Nominal short-term rate & 0 & Annual change & 10,5 & + \\
Nominal long-term rate & 0 & Annual change & 9,9 & + \\
Investment & 0 & Gap (HP trend) & 9,3 & + \\
Residential investment-to-GDP ratio & 3 & Annual growth & 7,0 & + \\
Spread & 0 & Gap (HP trend) & 4,2 & - \\
Credit (real) & 4 & Gap (linear trend) & 3,3 & - \\
Residential investment & 2 & Annual growth & 2,2 & + \\
Total investment-to-GDP ratio & 3 & Annual growth & 1,8 & + \\
Money (real) & 1 & Annual growth & 0,8 & + \\
Real long-term rate & 4 & Gap (HP trend) & 0,6 & - \\
Money-to-GDP ratio & 4 & Annual growth & 0,3 & + \\
Money & 4 & Annual growth & 0,2 & + \\
Credit & 0 & Gap (linear trend) & 0,2 & - \\
Current account-to-GDP ratio & 0 & No transf. & 0,1 & + \\
Real short-term rate & 2 & Annual change & 0,1 & + \\
\hline \hline
\end{tabular}

Table 8: Non-parametric analysis of potential determinants of the type of stock-price booms (costly vs. costless or low-cost). Notes: see previous Table.

We now consider the ability of our set of indicator variables to explain costly asset-price booms versus low-cost or costless booms.

Table 7 confirms previous intuitions regarding house-price developments. First, in a booming phase, an increase in the real interest rate will tend to increase the cost of an housing boom: 
this may stem from the fact that highly leveraged households will tend to see the real service of their debt increasing, raising the probability of their default and, as argued earlier, such an increase in interest rates will tend in addition to exacerbate both adverse selection and moral hazard problems on credit markets. Real indicators continue to play a significant role while credit still tends to dominate significantly monetary indicators.

Both above-trend real activity and house-price increases tend to characterize costly stock-price booms, immediately followed by nominal interest rates. Other variables tend to play a much lower role (see Table 8 ).

Overall, non-parametric tests tend to confirm the significant role of real economic activity and credit variables in shaping asset-price booms, in particular house price booms. These variables also tend to be the most relevant and robust in explaining costly asset-price booms. Interest rates tend to play a less significant role. Interestingly however, this role tends to be asymmetric and dependent upon the state of the economy: there is some evidence that low interest rates may contribute to trigger asset-price booms and that, once a boom has started, interest rates' hikes may increase the cost of this asset-price boom.

\section{The determinants of costly booms: a discrete-choice (logit) model}

We complement the non-parametric analysis by considering now the output of a logit-type approach. Such an approach will provide us with further information, in particular the marginal impact of a given variable to the probability of being in a boom or is a costly boom. One advantage of this approach compared to the signalling approach widely used in the early warning indicator literature is that is allows for statistical inference and tests.

In order to carry out our estimations, we will rely on the results of the KW procedure (presented in 4.2). For instance, regarding housing prices (see Table 5), the variables with the higher performances are real GDP and the investment variables (total and residential capital expenditures). The transformations selected by our procedures for these variables are deviation from the HP trend without any lag. The different variables computed on the basis of the credit series rank next (computed on the basis of annual growth). The annual change of the current-account-to-GDP ratio (without lag) rank next and the KW is highly significant. ${ }^{6}$ The lower part of Table 5 includes mainly the variables related to monetary aggregates and short- and long-term interest rates.

As a consequence, we select total investment, real credit, current account (\% of GDP) and longterm interest rate with the appropriate lags and transformation in order to run the logit estimation. Formally, let us denote with $y_{i t}$ a binary variable that is equal to 1 when country $i$ is experiencing

\footnotetext{
${ }^{6}$ Recall that under the null hypothesis of the KW test, the test statistics follows a $\chi^{2}(1)$ distribution, implying $1 \%$ and $5 \%$ critical values of, respectively, 10.8 and 3.84 .
} 
a boom in period $t$ (and 0 otherwise). ${ }^{7}$ The logit model postulates that the probability distribution of $y_{i t}$ conditional on vector $\mathbf{x}_{i t}$ is defined by:

$$
\mathbf{P}\left(y_{i t}=1 \mid \mathbf{x}_{i t}\right)=P\left(\mathbf{x}_{i t} \beta+\nu_{i}\right)
$$

where $P(z)=(1+\exp (-z))^{-1} .8$ The estimations are performed by including random effects. The results of the boom-vs-no-boom logit analysis for the four identification methodologies are presented in Tables 9 (housing-price booms) and 10 (stock-price booms).

The coefficients represent the marginal increase in the probability of a boom evaluated at the mean level of the other variables. These coefficients are normalized so as to facilitate the reading of the results. For instance, an increase of one standard deviation in real credit raises the probability of a house-price boom by 5.8 percentage points in the case of the moving average identification scheme. The most striking results are the following: above trend real activity, as captured by real GDP or total investment, and long-term interest rate variables are significant for the four identification methodologies; above trend real credit is significant for 3 identification methodologies out of 4 and its marginal contribution to the probability of a house-price boom ranks between 2.2 and 5.8 percentage points. According to our estimates, the increase in the probability of a house-price boom induced by a rise of 1 standard deviation of real GDP ranks between 6.6 and 18.5 percentage points according to the different identification methodologies. The annual change of the Current account (as a \% of GDP) is significant at the 1\% level only in the case of the "Extended HP" methodology. In this case, a decrease (i.e. deterioration) of the current account to GDP ratio by 1 standard deviation over one year increases the probability of a house-price boom by $2.3 \%$.

\footnotetext{
${ }^{7}$ In these estimations, we do not made distinction between costly and non-costly booms.

${ }^{8}$ Underlying this model is the variance component model $y_{i t}=1 \Longleftrightarrow \mathbf{x}_{i t} \beta+\nu_{i}+\varepsilon_{i t}>0$, where $\varepsilon_{i t}$ are i.i.d. logistic distributed with mean zero and variance $\sigma_{\varepsilon}^{2}=\pi^{2} / 3$.
} 


\begin{tabular}{|c|c|c|c|c|c|}
\hline Variable & Transform - Lag & Marg. Effect & Std. Err. & $\mathbf{Z}$ & p-value \\
\hline \multicolumn{6}{|c|}{ Detection method: Extended HP } \\
\hline Real GDP & Gap (HP trend) - 0 & 0.1082 & .0161 & 6.70 & 0.000 \\
\hline Total Investment & Gap (HP trend) - 0 & -0.0060 & .0123 & -0.49 & 0.621 \\
\hline Credit (real) & Annual growth - 0 & 0.0234 & .0080 & 2.93 & 0.003 \\
\hline Current Account (\% GDP) & Annual change - 0 & -0.0229 & .0075 & -3.04 & 0.002 \\
\hline Long-term interest rate & Gap (HP trend) -4 & -0.0235 & .0078 & -2.99 & 0.003 \\
\hline \multicolumn{6}{|c|}{ Detection method: Recursive HP } \\
\hline Real GDP & Gap (HP trend) - 0 & 0.0660 & .0158 & 4.16 & 0.000 \\
\hline Total Investment & Gap (HP trend) - 0 & 0.0399 & .0114 & 3.50 & 0.000 \\
\hline Credit (real) & Annual growth - 0 & 0.00907 & .0060 & 1.51 & 0.131 \\
\hline Current Account (\% GDP) & Annual change - 0 & -0.0130 & .0057 & -2.27 & 0.023 \\
\hline Long-term interest rate & Gap (HP trend) - 4 & -0.0160 & .0058 & -2.72 & 0.006 \\
\hline \multicolumn{6}{|c|}{ Detection method: Moving average } \\
\hline Real GDP & Gap (HP trend) - 0 & 0.1857 & .0229 & 8.08 & 0.000 \\
\hline Total Investment & Gap (HP trend) - 0 & 0.0112 & .0212 & 0.53 & 0.598 \\
\hline Credit (real) & Annual growth - 0 & 0.0584 & .0142 & 4.09 & 0.000 \\
\hline Current Account (\% GDP) & Annual change - 0 & -0.0266 & .01271 & -2.10 & 0.036 \\
\hline Long-term interest rate & Gap (HP trend) - 4 & -0.0812 & .0131 & -6.20 & 0.000 \\
\hline \multicolumn{6}{|c|}{ Detection method: Band-pass filter } \\
\hline Real GDP & Gap (HP trend) - 0 & 0.1015 & .016 & 6.35 & 0.000 \\
\hline Total Investment & Gap (HP trend) -0 & 0.0393 & .0135 & 2.91 & 0.004 \\
\hline Credit (real) & Annual growth - 0 & 0.0221 & .0086 & 2.57 & 0.010 \\
\hline Current Account (\% GDP) & Annual change - 0 & -0.0143 & .0075 & -1.89 & 0.059 \\
\hline Long-term interest rate & Gap (HP trend) -4 & -0.04136 & .0083 & -4.95 & 0.000 \\
\hline \multicolumn{6}{|c|}{$\begin{array}{l}\text { Note: (a) The model is } P\left(y_{i t}=1 \mid x_{i t}\right)=P\left(x_{i t} \beta+\nu_{i}\right) \text { where, for any period } t \text { and country } i \text {, } \\
y_{i t} \text { is equal to } 0 \text { (no boom) or } 1 \text { (boom) and } P(z)=(1+\exp (-z))^{-1} ;(\mathrm{b}) \text { The marginal effect } \\
\text { corresponds to the impact off a 1st.dev. of the considered variable on } P\left(y_{i t}=1\right) \text {. }\end{array}$} \\
\hline
\end{tabular}

Table 9: Housing-price boom vs. no boom 


\begin{tabular}{|c|c|c|c|c|c|}
\hline Variable & Transform - Lag & Marg. Effect & Std. Err. & $\mathbf{z}$ & p-value \\
\hline \multicolumn{6}{|c|}{ Detection method: Extended HP } \\
\hline Credit & Gap (HP trend) - 3 & .0567697 & .01023 & 5.55 & 0.000 \\
\hline Housing prices & Gap (HP trend) - 4 & -.1085982 & .01223 & -8.88 & 0.000 \\
\hline Total Investment & Annual growth - 0 & .0910883 & .01233 & 7.39 & 0.000 \\
\hline Long-term interest rate & Annual change - 3 & -.0543498 & .01025 & -5.30 & 0.000 \\
\hline \multicolumn{6}{|c|}{ Detection method: Recursive HP } \\
\hline Credit & Gap (HP trend) -3 & .0379146 & .0084 & 4.52 & 0.000 \\
\hline Housing prices & Gap (HP trend) - 4 & -.072328 & .00903 & -8.01 & 0.000 \\
\hline Total Investment & Annual growth - 0 & .0327945 & .00939 & 3.49 & 0.000 \\
\hline Long-term interest rate & Annual change - 3 & -.0377399 & .00796 & -4.74 & 0.000 \\
\hline \multicolumn{6}{|c|}{ Detection method: Moving average } \\
\hline Credit & Gap (HP trend) - 3 & -.0115782 & .0111 & -1.04 & 0.297 \\
\hline Housing prices & Gap (HP trend) -4 & -.1156738 & .01187 & -9.75 & 0.000 \\
\hline Total Investment & Annual growth - 0 & .0778618 & .01235 & 6.31 & 0.000 \\
\hline Long-term interest rate & Annual change - 3 & -.0626359 & .01088 & -5.76 & 0.000 \\
\hline \multicolumn{6}{|c|}{ Detection method: Band-pass filter } \\
\hline Credit & Gap (HP trend) - 3 & .0870282 & .00903 & 9.63 & 0.000 \\
\hline Housing prices & Gap (HP trend) - 4 & -.0699275 & .0094 & -7.44 & 0.000 \\
\hline Total Investment & Annual growth - 0 & .0834127 & .01014 & 8.23 & 0.000 \\
\hline Long-term interest rate & Annual change - 3 & -.0502437 & .00878 & -5.72 & 0.000 \\
\hline \multicolumn{6}{|c|}{$\begin{array}{l}\text { Note: (a) The model is } P\left(y_{i t}=1 \mid x_{i t}\right)=P\left(x_{i t} \beta+\nu_{i}\right) \text { where, for any period } t \text { and country } i \\
y_{i t} \text { is equal to } 0 \text { (no boom) or } 1 \text { (boom) and } P(z)=(1+\exp (-z))^{-1} ;(\text { b) The marginal effect } \\
\text { corresponds to the impact off a } 1 \text { st.dev. of the considered variable on } P\left(y_{i t}=1\right) \text {. }\end{array}$} \\
\hline
\end{tabular}

Table 10: Stock-price boom vs. no boom 


\begin{tabular}{|c|c|c|c|c|c|}
\hline Variable & Transform - Lag & Marg. Effect & Std. Err. & $\mathbf{z}$ & p-value \\
\hline \multicolumn{6}{|c|}{ Detection method: Extended HP } \\
\hline Real long term interest rate & No transf. -4 & 0.259 & 0.06941 & 3.74 & 0.000 \\
\hline Total investment & Annual growth - 1 & 0.292 & 0.08253 & 3.54 & 0.000 \\
\hline Real credit & Annual growth - 1 & -0.105 & 0.0592 & -1.78 & 0.075 \\
\hline Real stock prices & Gap (HP trend) - 0 & 0.2805 & 0.0821 & 3.42 & 0.001 \\
\hline \multicolumn{6}{|c|}{ Detection method: Recursive HP } \\
\hline Real long term interest rate & No transf. -4 & 0.2582 & 0.0699 & 3.69 & 0.000 \\
\hline Total investment & Annual growth - 1 & 0.0548 & 0.05103 & 1.07 & 0.282 \\
\hline Real credit & Annual growth - 1 & 0.3492 & 0.0759 & 4.60 & 0.000 \\
\hline Real stock prices & Gap (HP trend) -0 & 0.0608 & 0.0561 & 1.09 & 0.278 \\
\hline \multicolumn{6}{|c|}{ Detection method: Moving average } \\
\hline Real long term interest rate & No transf. -4 & 0.2771 & 0.0368 & 7.51 & 0.000 \\
\hline Total investment & Annual growth - 1 & 0.0214 & 0.0289 & 0.74 & 0.457 \\
\hline Real credit & Annual growth - 1 & 0.0553 & 0.0262 & 2.11 & 0.035 \\
\hline Real stock prices & Gap (HP trend) -0 & 0.1599 & 0.0308 & 5.18 & 0.000 \\
\hline \multicolumn{6}{|c|}{ Detection method: Band-pass filter } \\
\hline Real long term interest rate & No transf. -4 & 0.1020 & 0.0411 & 2.48 & 0.013 \\
\hline Total investment & Annual growth - 1 & 0.0197 & 0.0176 & 1.12 & 0.263 \\
\hline Real credit & Annual growth - 1 & -0.0049 & 0.0122 & -0.41 & 0.685 \\
\hline Real stock prices & Gap (HP trend) - 0 & 0.0167 & 0.0126 & 1.32 & 0.187 \\
\hline \multicolumn{6}{|c|}{$\begin{array}{l}\text { Note: (a) The model is } P\left(y_{i t}=1 \mid x_{i t}\right)=P\left(x_{i t} \beta+\nu_{i}\right) \text { where, for any period } t \text { and country } i \text {, } \\
y_{i t} \text { is equal to } 0 \text { (non-costly boom) or } 1\left(\text { costless or low-cost boom) and } P(z)=(1+\exp (-z))^{-1}\right. \\
\text { (b) The marginal effect corresponds to the impact off a } 1 \text { st.dev. of the considered variable on } P\left(y_{i t}=1\right) \text {. }\end{array}$} \\
\hline
\end{tabular}

Table 11: Housing-price costly boom vs. non-costly boom 


\begin{tabular}{|c|c|c|c|c|c|}
\hline Variable & Transform - Lag & Marg. Effect & Std. Err. & $\mathbf{z}$ & p-value \\
\hline \multicolumn{6}{|c|}{ Detection method: Extended HP } \\
\hline Real GDP & Gap (HP trend) - 0 & .1073131 & .03382 & 3.17 & 0.002 \\
\hline Housing prices & Annual growth - 3 & .0610527 & .02945 & 2.07 & 0.038 \\
\hline Spread (LT rate - ST rate) & Gap (HP trend) - 0 & -.0306102 & .02507 & -1.22 & 0.222 \\
\hline Credit (real) & Gap (HP trend) -4 & -.0335127 & .03041 & -1.10 & 0.270 \\
\hline \multicolumn{6}{|c|}{ Detection method: Recursive HP } \\
\hline Real GDP & Gap (HP trend) - 0 & .2067904 & .02912 & 7.10 & 0.000 \\
\hline Housing prices & Annual growth - 3 & .042553 & .02413 & 1.76 & 0.078 \\
\hline Spread (LT rate - ST rate) & Gap (HP trend) - 0 & -.1170251 & .02355 & -4.97 & 0.000 \\
\hline Credit (real) & Gap (HP trend) -4 & -.0830916 & .02376 & -3.50 & 0.000 \\
\hline \multicolumn{6}{|c|}{ Detection method: Moving average } \\
\hline Real GDP & Gap (HP trend) - 0 & .2270219 & .0769 & 2.95 & 0.003 \\
\hline Housing prices & Annual growth - 3 & -.0232369 & .03369 & -0.69 & 0.490 \\
\hline Spread (LT rate - ST rate) & Gap (HP trend) - 0 & -.0113261 & .02795 & -0.41 & 0.685 \\
\hline Credit (real) & Gap (HP trend) -4 & -.0459461 & .02844 & -1.62 & 0.106 \\
\hline \multicolumn{6}{|c|}{ Detection method: Band-pass filter } \\
\hline Real GDP & Gap (HP trend) - 0 & .3043812 & .04517 & 6.74 & 0.000 \\
\hline Housing prices & Annual growth - 3 & .0482078 & .03048 & 1.58 & 0.114 \\
\hline Spread (LT rate - ST rate) & Gap (HP trend) - 0 & -.0726526 & .03026 & -2.40 & 0.016 \\
\hline Credit (real) & Gap (HP trend) -4 & -.007206 & .03226 & -0.22 & 0.823 \\
\hline
\end{tabular}

Note: (a) The model is $P\left(y_{i t}=1 \mid x_{i t}\right)=P\left(x_{i t} \beta+\nu_{i}\right)$ where, for any period $t$ and country $i$,

$y_{i t}$ is equal to 0 (non-costly boom) or 1 ( costless or low-cost boom) and $P(z)=(1+\exp (-z))^{-1}$

(b) The marginal effect corresponds to the impact of a 1st.dev. of the considered variable on $P\left(y_{i t}=1\right)$.

Table 12: Stock-price costly boom vs. non-costly boom

The probability of a stock-price boom (vs. no boom) is also positively and significantly influenced by above-trend credit in 3 cases out of 4 , with a marginal impact of around $5.5 \%$ on average. Annual declines in long-term interest rates also contribute to increase the probability of a stock-price boom, with a marginal impact of around 5\%, a result being robust across methodologies. Stock price booms are also positively influenced by total investment rate of growth. Finally, it seems that house-price declines are robust predictors of stock-price booms, which may reflect portfolio rebalancing effects. The estimated probability of a housing boom by country according to the different identification schemes are presented in Figures 18 to 21. The estimated probability of a stock-price boom by country according to the different identifiaction schemes are presented in Figures 26 to 29. The charts provide an illustration for each country and for the two asset prices of how well the logit model perform in order to predict a boom for each identification methodologies.

We analyze now the determinants of the probability of a costly asset-price boom conditional upon the fact the economy is already in a booming phase. This means that, to carry out our logit regressions, we exclude those observations that do not correspond to booms.

Formally, in the logit equation, the binary variable $y_{i t}$ is set equal to 1 (respectively to 0 ) when country $i$ is experiencing a costly (respectively a costless or low-cost) boom in period $t$. Table 11 displays the results for costly house-price booms. The most robust results are found for the 
real long-term interest rates in level and the above trend stock-price index which all contribute positively to the probability of a house-price boom. The marginal impact is however quite volatile depending on the methodology, ranging from 10 to 27 percentage points for long-term interest rates and 1 to 28 percentage points for stock prices. The rate of growth of credit is positively signed in 2 cases out of 4 . The marginal impact of total investment, which is positively signed irrespective of the identification method, is not always statistically significant. The estimated probability of a costly (vs. low-cost or costless) housing boom according to the different identification schemes are presented in Figures 22 to 25 in the appendix. The similar estimated probability for a costly (vs. low-cost or costless) stock-price boom are presented in Figures 30 to 33 (see appendix).

It is more difficult to find robust explanatory variables to account for costly stock-price booms. From Table 12, only above trend real GDP would do the trick. Its marginal contribution varies a lot depending on the identification methodology but it is above 20 percentage points for 3 methods out of 4 , that is a positive output gap increase the probability of a costly stock-price boom by almost 20 percentage points.

\section{Policy implications and conclusion}

In this paper, we try to assess the robustness of several asset-price boom-bust identification procedures. We find that:

1) the identification of an asset-price boom or bust remains challenging ex ante and ex post despite the fact that the methodologies implemented in the literature differ sometimes only marginally. There remain critical choices regarding the determination of key parameters (method and degree of smoothing, real time data, magnitude of deviation from trend etc.). Implementing four of the most popular methods used in the literature, we find that these methods deliver between $45 \%$ and $63 \%$ consistent signals in the case of stock prices and $53 \%$ and $75 \%$ in the case of housing prices. Thus, it seems that housing-price booms and busts are more consistently and robustly identified than stock-price cycles.

2) Regarding the main features of the identified episodes, we find that stock-price boom-bust cycles are more frequent but shorter-lived than house-price ones. They also tend to be less costly, meaning that a significant proportion of stock-price busts is not associated with a costly recession. On the contrary, most house-price booms tend to turn into costly recessions.

3) Looking at diffusion indices, we find that a significant proportion of stock-price boom and bust episodes tend to occur simultaneously across our set of 18 OECD countries: in most cases, 15 or 16 out of 18 countries are experiencing simultaneously a boom or a bust. This proportion falls to generally 5 out of 18 in the case of house-prices booms and busts, but in the last episodes where this proportion increased to 10 out of 18 countries. Therefore, it is likely that stock-price cycles are mainly driven by global factors whereas housing-price cycles still remain local phenomena. The 
last housing cycle would be singular in this respect even though this diagnostic is not necessarily robust across methods.

4) There is a case to distinguish costly asset-price booms from other booms, which would implies to rely on state-contingent macro-prudential policies rather than on mechanistic or systematic instrument rules. It would be detrimental to long-term growth to consider that all credit or all asset-price expansions are dangerous. However, such an identification can't be performed ex ante.

5) Looking at the main determinants, we have relied so far on a limited set of variables, mostly macroeconomic variables. We have started to gather information on banks' balance sheets at the aggregate level but have not exploited yet their information content as so far our data base is limited (usually starting in the late 1980's), incomplete (it does not cover our 18 OECD countries) and annual (instead of quarterly). However, the preliminary results are already useful for a macroprudential perspective: we find first that it is easier to account for housing-price developments that for stock prices: in the latter case, financial factors, expectations or animal spirits are not encapsulated in our database. We find that credit variables play indeed in both cases a significant role in shaping asset-price booms and in particular costly ones. We also find that above-trend activity (as measured by real GDP or output gap) also characterize costly asset-price booms. Finally, we find evidence that interest rates play an asymmetric role: their low level is likely to trigger an asset-price boom and an interest rate hike in the booming phase is conducive to a bust or a costly boom.

From these results, we can draw the following policy implications:

1) If the scope of macro-prudential regulation is to prevent asset-price bubbles or booms, it is not clear why macro-prudential authorities will be better equipped than central banks, unless they rely on a different set of information variables (eventually individual data on banks' balance sheets) to identify these episodes ex ante. This has still to be clearly assessed. Therefore, the ex ante identification of a bubble remains a challenging task.

2) On top of that, it seems important to distinguish amongst different asset classes as their behavior, main determinants and main features may vary a lot. From our results, there is some scope to focus on housing-price bubbles or booms rather than on stock-price developments: first, because most households and firms finance their house or commercial real estate through bank lending. Therefore, it is easier to tackle house-price developments through macro-prudential instruments. Indeed, we find some evidence that credit developments are a major and significant determinant of house-price booms meaning that overall bank balance sheets, composition and leverage matter. Second, because house-price booms are more likely to turn into severe economic contractions than stock prices. This may relates to the facts that, consistent with the "credit view", most house-price busts or costly house-price booms can been seen as "credit booms gone wrong" as put forward by economists like Minsky (1977) or Kindleberger (1978). This view would 
also be consistent with recent declarations by Mishkin (2009) arguing that not all asset bubbles are alike and distinguishing between (costly) credit bubbles and (costless or low-cost) speculative bubbles.

3) This point also makes the case against aggregating asset prices into a single index. Indeed, we find in our regressions that specific asset prices also contain useful information for other asset classes' dynamics. It can also be argued that "lean against the wind policies" by central banks should concentrate on the aggregated effects of asset-price bubbles. This is different from a macroprudential perspective where regulation can be applied in a more disaggregated fashion (for instance by tightening credit standards on specific loan categories whereas relaxing or keeping them constant on others).

4) In order to avoid output and welfare losses, macro-prudential authorities should focus on costly booms only, leaving aside low-cost or costless booms. This militates in favor of statecontingent policies, the idea being to address excess-credit developments but not credit expansion per se. This may call to limit recourse to automatic or instrument rules but rather develop macroprudential regulation under pillar 2 of Basel 2.

5) How to delineate the responsibilities with monetary policy? Indeed, central banks are also concerned with asset-price booms to the extent they may endanger their primary objective of price stability. They are also concerned with unsustainable real and credit developments. As shown in our analysis, the manipulation of interest rates during a boom is effective in the sense it may trigger the bust. This may also be seen as an argument against popping bubbles. From that angle, as it appears difficult to consider that central banks instruments are completely independent from macro-prudential ones, one might think at the following delineation between monetary and macroprudential policies. Monetary policy has a clear and primary objective of price stability. It is in charge of the management of economic activity, in particular of controlling and offsetting demand shocks for a given supply. A central bank has the ability to change its main instruments (the interest rates) when deemed appropriate to reach its ultimate goal of price stability in the medium run. Macro-prudential policies are of a different nature: they have to address structural imbalances so as to avoid excessive risk taking and systemic risk. But one cannot change regulations, be it of a macro-type, as frequently as interest rates. Moreover, macro-prudential regulation should rather be state-dependent. A case can be made for instance in the wake of a positive and permanent productivity shock. Should automatic macro-prudential policies be in place, this would result in constraints on bank lending whereas the central bank would try to push up falling inflation by cutting its policy rate. To avoid such a conflict between the price stability and the financial stability objectives, macro-prudential policies should therefore focus on excessive developments, in particular in credit markets, and provide good incentives to avoid excessive risk taking in the financial industry. In this respect, they would also be able to address sectorial developments (for 
instance reducing unsustainable capital accumulation in one specific sector) whereas "one-size fits all" monetary policy would not.

6) From this perspective, enlarging the scope of macro-prudential regulation to prevent asset bubbles may be too ambitious given our limited ability to identify bubbles ex ante and due to the very specific behavior of each type of asset. Dealing with financial fragility, from a structural perspective, might indeed be more appropriate. On top of monetary policy and macro-prudential regulation, one should also consider other tools such as sector specific regulations or alternatively Pigouvian taxation to address negative externalities at the origin of systemic risks. 


\section{References}

1. R. Adalid and C. Detken. Liquidity shocks and Asset Price Boom/Bust Cycles. ECB Working Paper No. $732,2007$.

2. T. Adrian and H. S. Shin. Financial intermediaries, financial stability and monetary policy. Working Paper Series No. 346, Federal Reserve Bank of New York, September 2008.

3. L. Agnello and L. Schuknecht. Booms and busts in housing markets determinants and implications. ECB Working Paper No. 1071, 2009.

4. L. Alessi and C. Detken. Real Time' Early Warning Indicators for Costly Asset Price Boom/Bust Cycles: A Role for Global Liquidity. ECB Working Paper No. 1039, 2009.

5. A. Barajas, G. Dell'Ariccia and A. Levchenko. Credit booms: the Good, the Bad and the Ugly. International Monetary Fund, manuscript, 2008.

6. B. Bernanke and A. Blinder. The Federal Funds Rate and the Channels of Monetary Policy Transmission. American Economic Review 82(4):901-21, 1992.

7. B. Bernanke, M. Gertler and S. Gilchrist. The financial accelerator in a quantitative business cycle framework. In Handbook of Macroeconomics, vol. 1, edited by J. B. Taylor and M. Woodford. Amsterdam: Elsevier, pp. 1341-93, 1999.

8. M. D. Bordo and O. Jeanne. Monetary Policy and Asset Prices: Does 'Benign Neglect' Make Sense?. International Finance, 5:2, pp. 139-164, 2002.

9. M. D. Bordo and D. Wheelock. Monetary Policy and Asset Prices: a Look Back at US Stock Market Booms. NBER WP 10704, 2004.

10. C. Borio and P. Lowe. Asset Prices, financial and monetary stability: exploring the nexus. BIS Working paper, No 114, 2002.

11. S. Cecchetti. Measuring the Macroeconomic Risks Posed by Asset Price Boom. NBER WP 12542, 2006.

12. A. Clare and R. Courtenay. Assessing the impact of macroeconomic news announcements on securities prices under different monetary policy regimes? Bank of England Working Papers No.125, 2001.

13. C. Detken and F. Smets. Asset Price Booms and Monetary Policy. ECB Working Paper, No. 364, 2004. Also published in Siebert, H. (2004), (ed.), Macroeconomic Policies in the World Economy, Springer: Berlin. 
14. A. Fatas, P. Kannan, P. Rabanal and A. Scott. Lessons from Asset Price Fluctuations for Monetary Policy. World Economic Outlook, International Monetary Fund, September 2009.

15. D. Gerdesmeier, H.-E. Reimers, and B. Roffia, Asset Price Misalignments and the Role of Money and Credit. ECB Working Paper No. 1068, 2009.

16. C. Goodhart and B. Hofmann, House prices, money, credit, and the macroeconomy. Oxford Review of Economic Policy, Volume 24, Number 1, 2008, pp.180-205

17. R. Gurkaynak, Econometric tests of asset-price bubbles: taking stock. Journal of Economic Surveys, Vol. 22, No. 1, pp. 166-186, 2008.

18. D. Harding and A. Pagan. Dissecting the cycle: a methodological investigation. Journal of Monetary Economics n.49 pp. 365-381, 2002.

19. International Monetary Fund. Lessons for monetary policy from asset price fluctuations. World Economic Outlook, Chapter 3, pp. 93-120, October 2009.

20. A. Jaeger and L. Schuknecht. Boom-Bust Phases in Asset Prices and Fiscal Policy Behavior. Emerging Markets Finance and Trade, M.E. Sharpe, Inc., vol. 43(6), pages 45-66, November, 2007.

21. C. Kindleberger. Manias, Panics, and Crashes: A History of Financial Crises. New York: Basic Books, 1978.

22. J.P. Landau. Bubbles and macro-prudential supervision. Remarks at the Joint conference on the "Future of Financial Regulation", Banque de France and Toulouse School of Economics, Paris, 28 January 2009.

23. E. Mendoza, and M. E. Terrones. An Anatomy of Credit Booms: Evidence from Macro Aggregates and Micro Data. NBER Working Paper No. 14049, 2008.

24. H. Minsky. The Financial Instability Hypothesis: an Interpretation of Keynes and Alternative to Standard Theory. Challenges (March-April): 20-27, 1977.

25. F. Miskhin. Not all bubbles present a risk to the economy. The Financial Times, November 9, 2009.

26. M. Musard-Gies. Do ECB's statements steer short-term and long-term interest rates in the eurozone. The Manchester School, 74, 116-139, 2006.

27. R. Rancière, A. Tornell and F. Westermann. Systemic Risk and Growth. Quarterly Journal of Economics, 123 (1), pp. 359-406, 2008.

28. M. Schularick and A. M. Taylor (2009). Credit Booms Gone Bust: Monetary Policy, Leverage Cycles and Financial Crises, 1870-2008. CEPR Discussion Paper No 7570, November 2009. 
29. M. Socorro Gochoco-Bautista. Asset prices and monetary policy: booms and fat tails in East Asia. BIS Working Paper No. 243, 2008.

30. D.J. Sheshkin. Handbook of parametric and nonparametric statistical procedures. CRC Press, New York, NY, 1997. 
MA IMMO

AUS BEL CAN CHE DEU DNK ESP FIN FRA GBR IRL ITA JPN NLD NOR NZL SWE USA

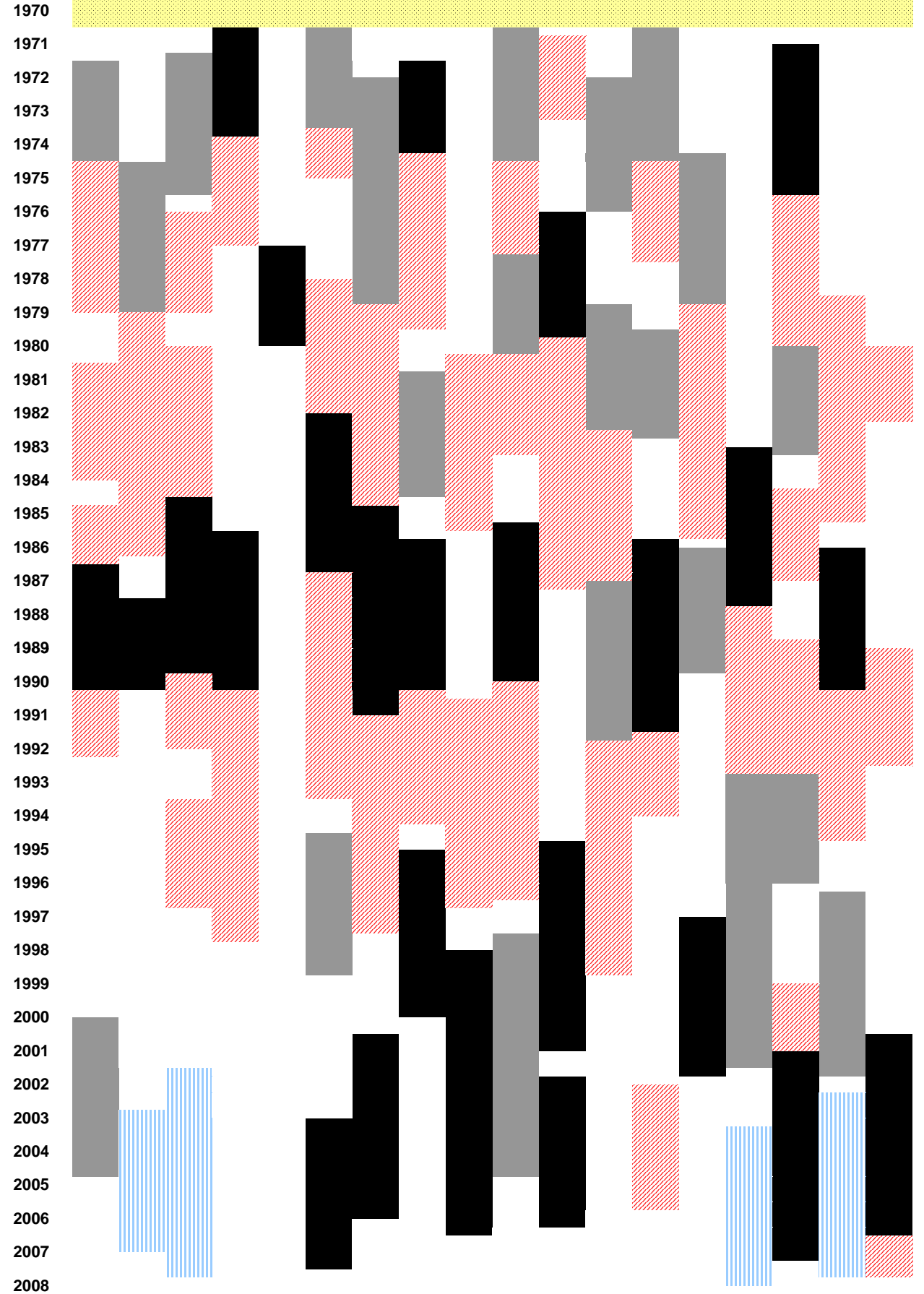

Figure 9: Housing prices: boom and bust identification - Moving Average method (yellow: not available, black: costly boom, grey: non-costly boom, red: bust, blue: not-qualified boom) 


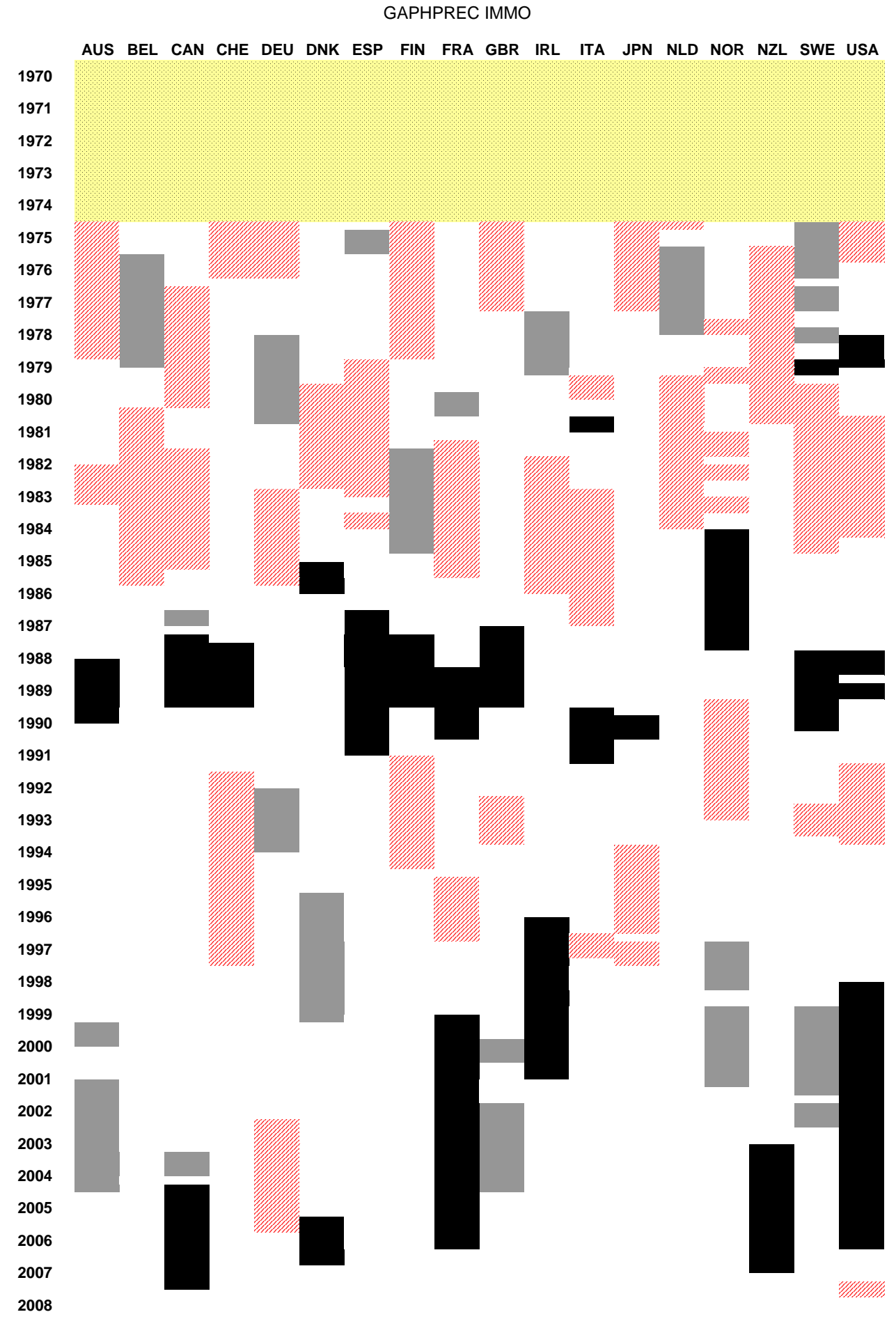

Figure 10: Housing prices: boom and bust identification - Recursive HP method (yellow: not available, black: costly boom, grey: non-costly boom, red: bust, blue: not-qualified boom) 
GAPHPAUGM IMMO

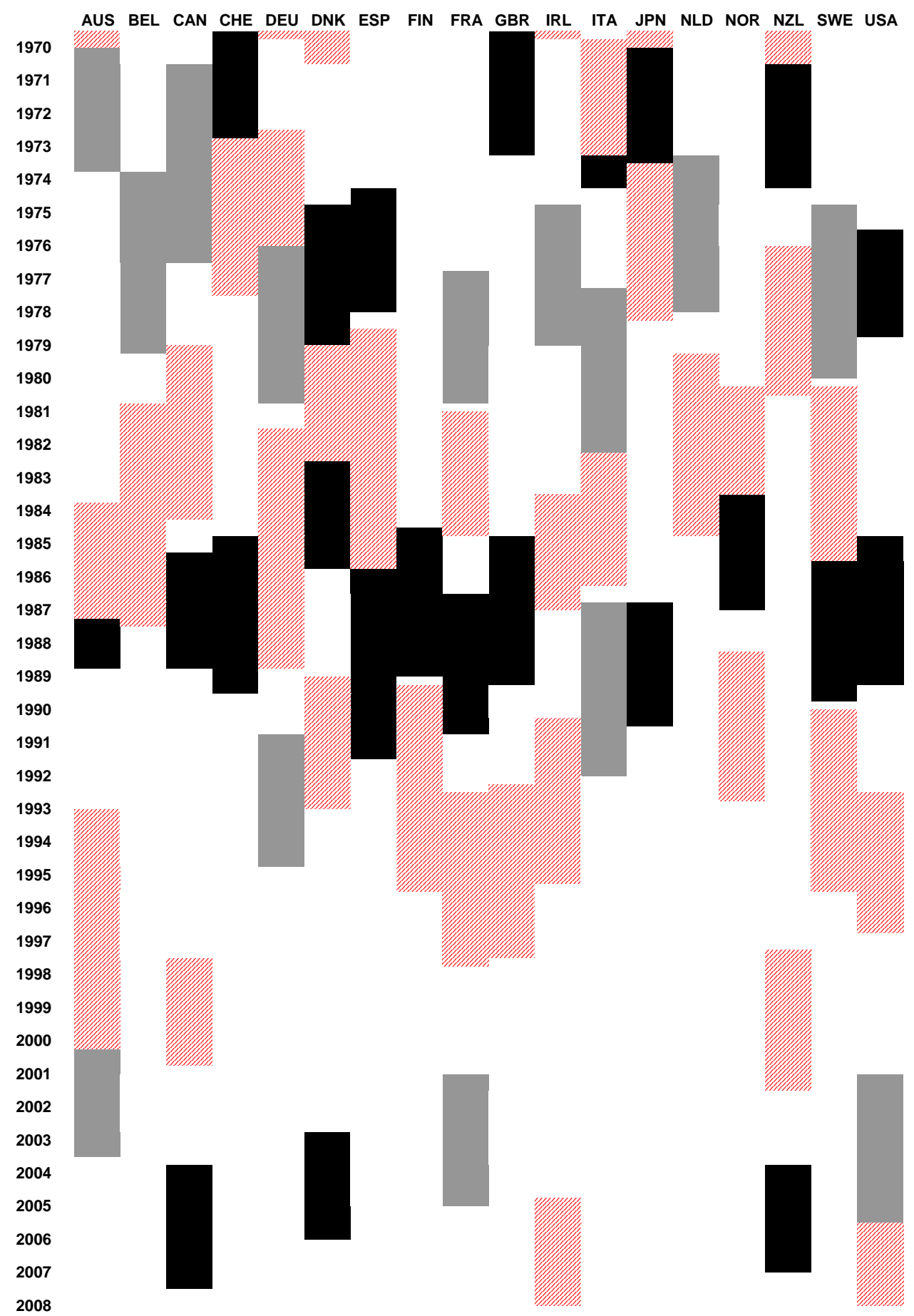

Figure 11: Housing prices: boom and bust identification - HP extended method (yellow: not available, black: costly boom, grey: non-costly boom, red: bust, blue: not-qualified boom) 
OPTLOC IMMO

AUS BEL CAN CHE DEU DNK ESP FIN FRA GBR IRL ITA JPN NLD NOR NZL SWE USA

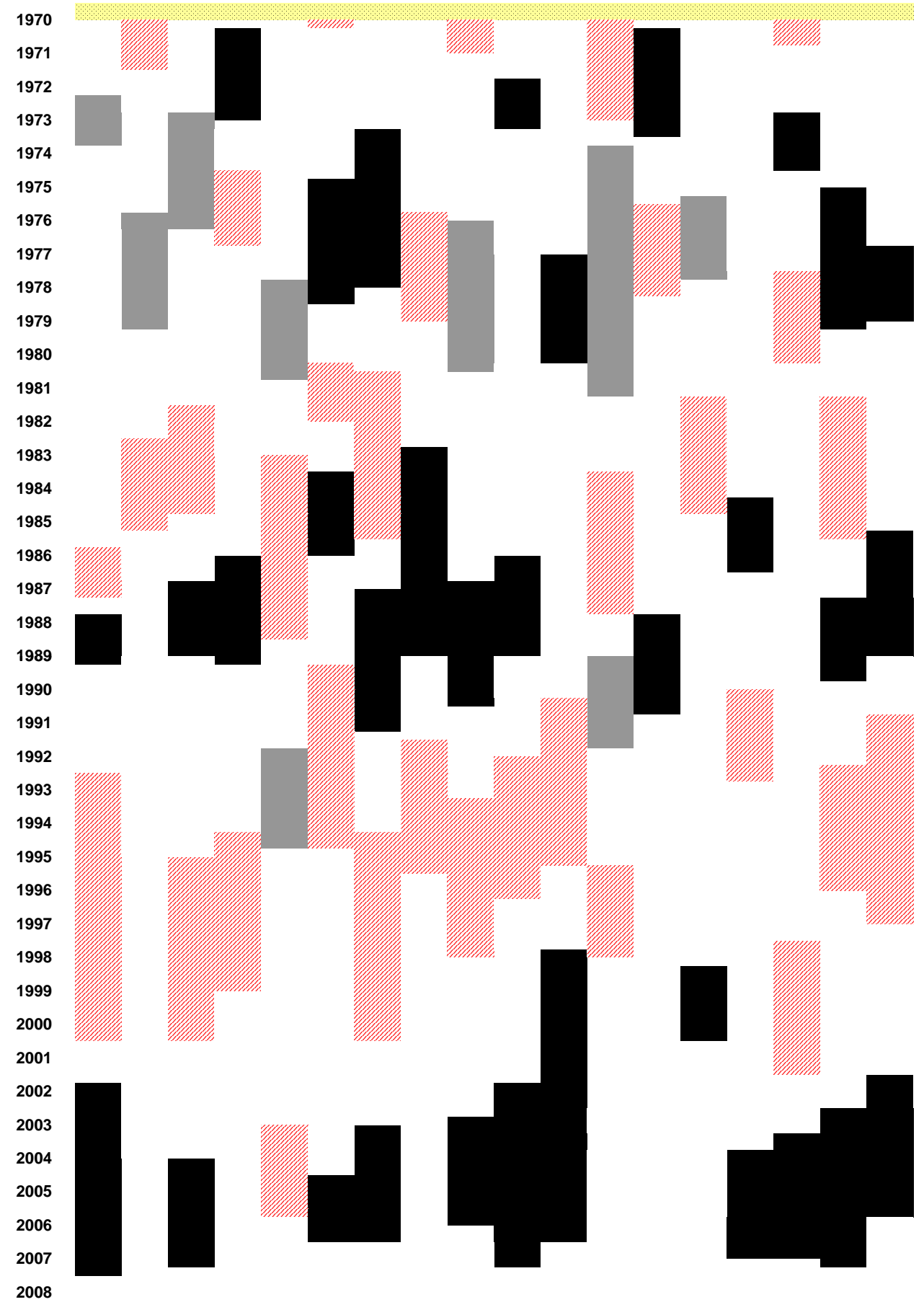

Figure 12: Housing prices: boom and bust identification - Band pass filter method (yellow: not available, black: costly boom, grey: non-costly boom, red: bust, blue: not-qualified boom) 
MA ACT

AUS BEL CAN CHE DEU DNK ESP FIN FRA GBR IRL ITA JPN NLD NOR NZL SWE USA

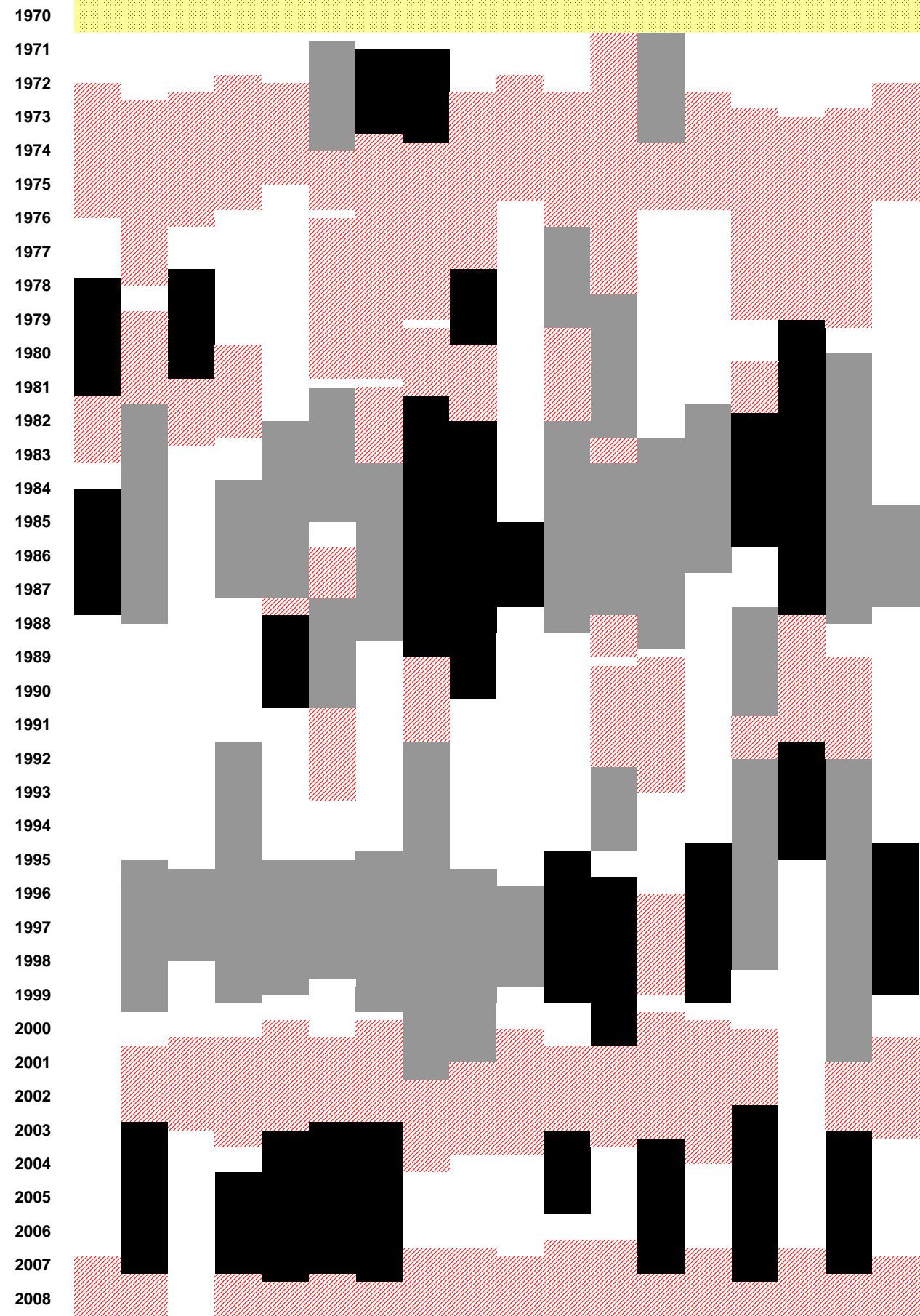

Figure 13: Stock prices: boom and bust identification - Moving Average method (yellow: not available, black: costly boom, grey: non-costly boom, red: bust, blue: not-qualified boom) 
GAPHPREC ACT

AUS BEL CAN CHE DEU DNK ESP FIN FRA GBR IRL ITA JPN NLD NOR NZL SWE USA

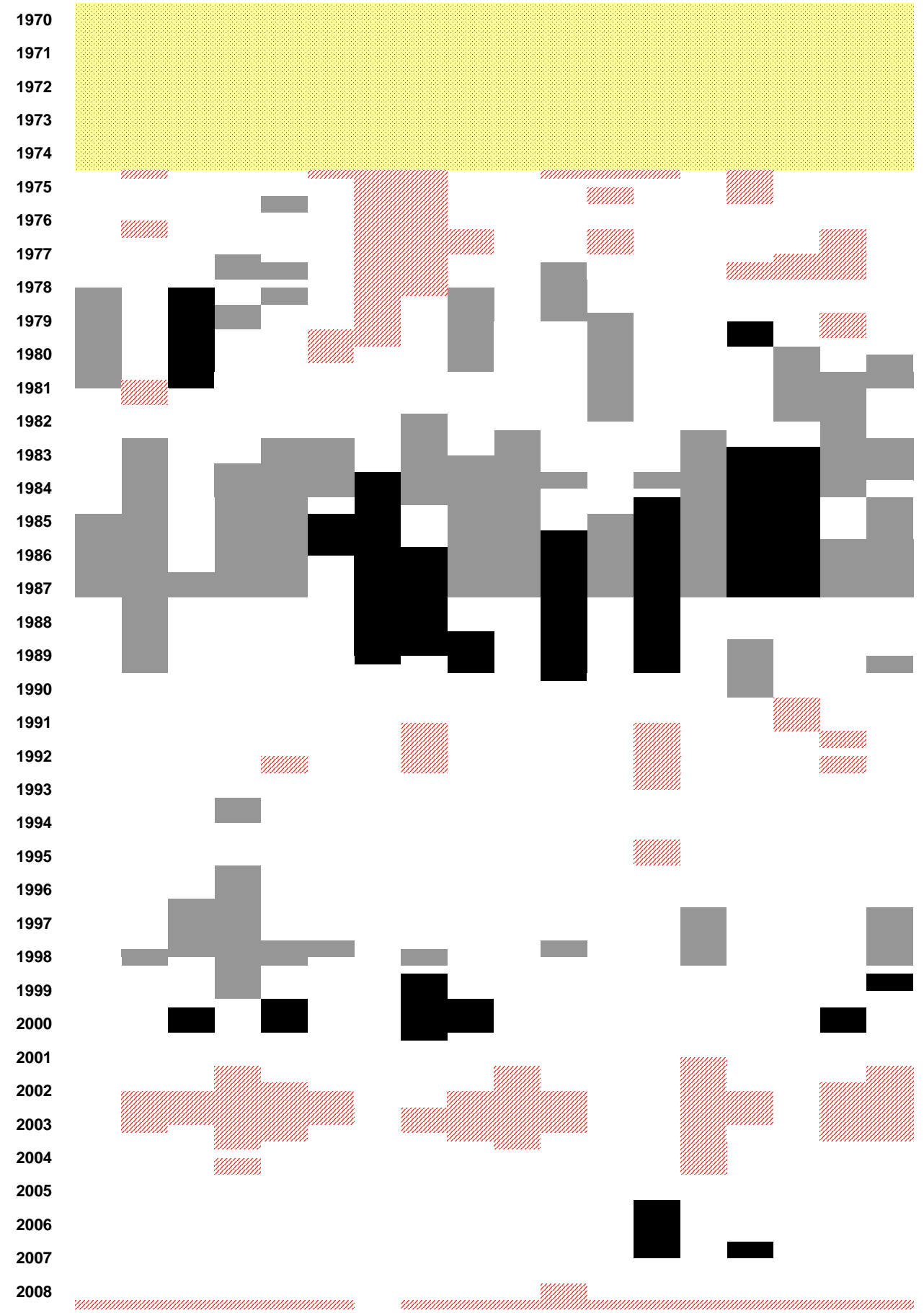

Figure 14: Stock prices: boom and bust identification - Recursive HP method (yellow: not available, black: costly boom, grey: non-costly boom, red: bust, blue: not-qualified boom) 


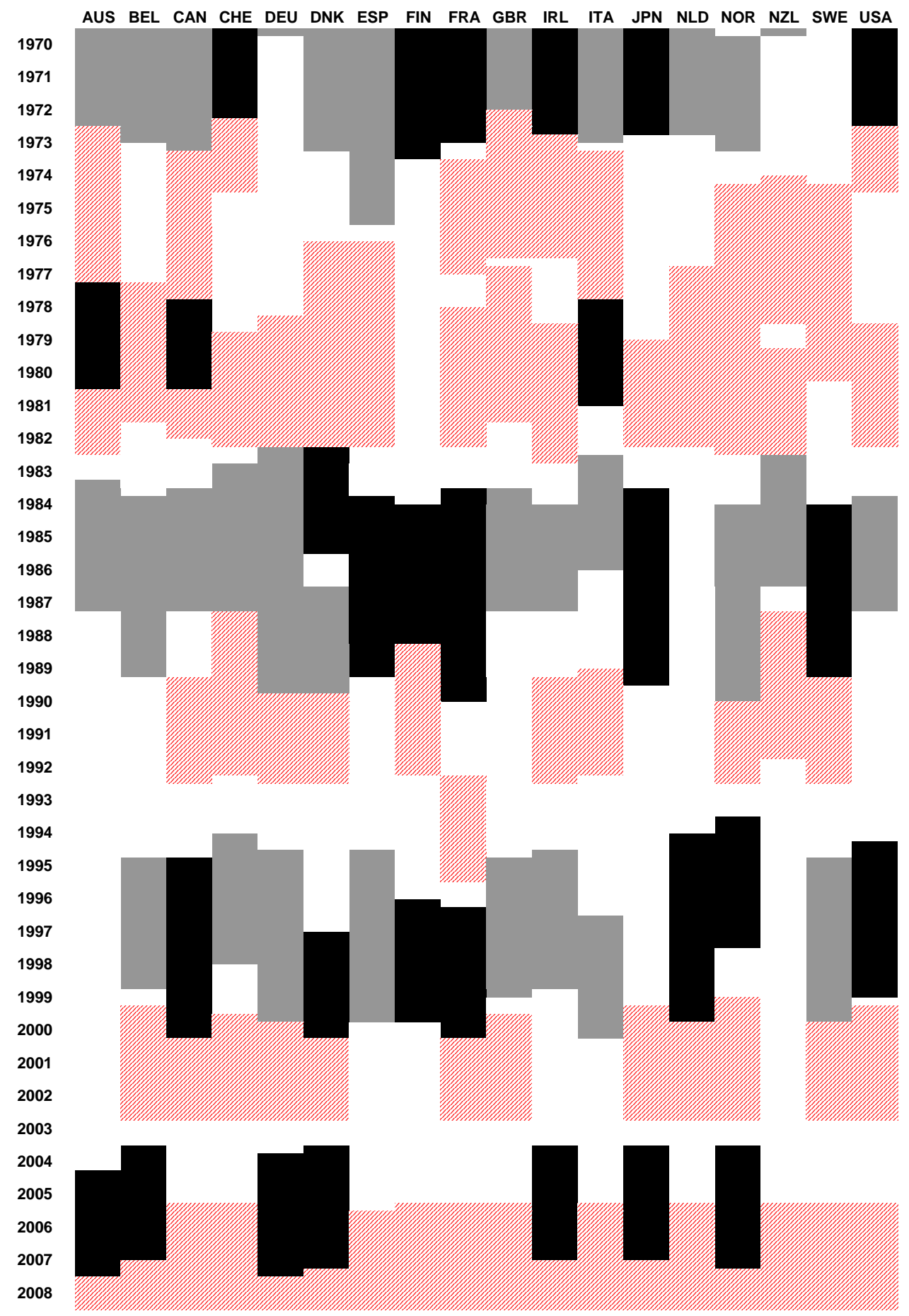

Figure 15: Stock prices: boom and bust identification - HP extended (yellow: not available, black: costly boom, grey: non-costly boom, red: bust, blue: not-qualified boom) 


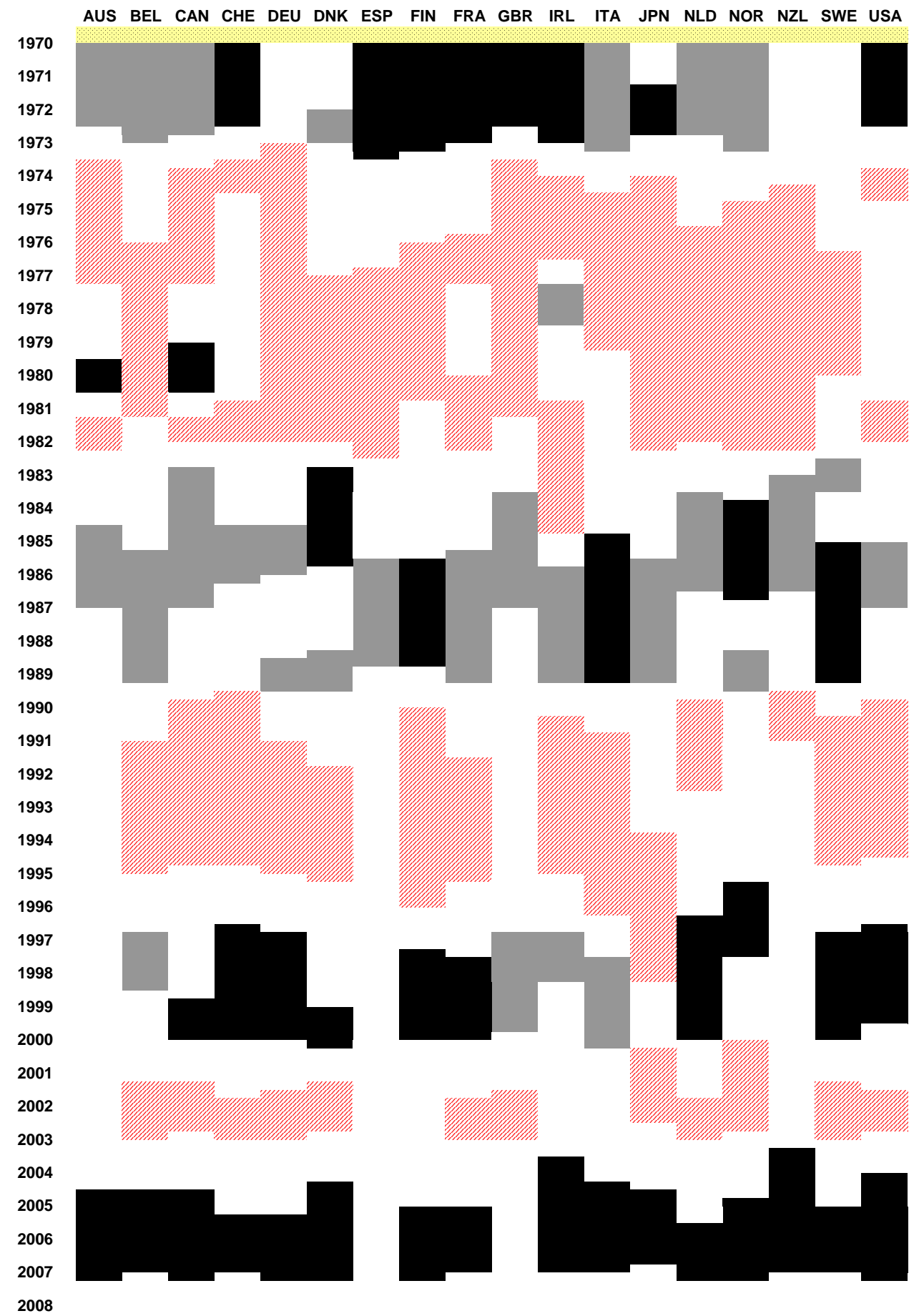

Figure 16: Stock prices: boom and bust identification - Band pass filter method (yellow: not available, black: costly boom, grey: non-costly boom, red: bust, blue: not-qualified boom) 

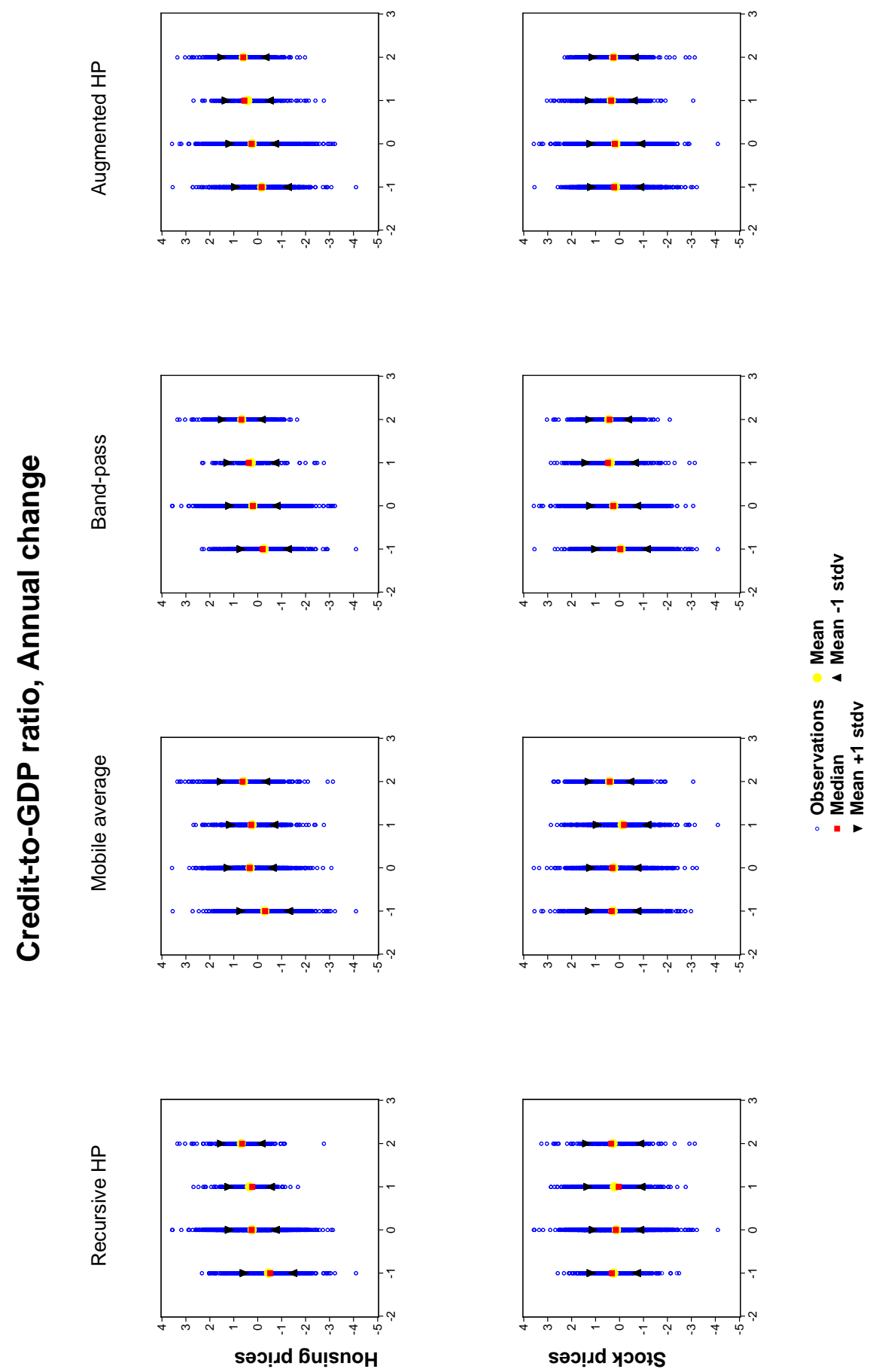

Figure 17: Preliminary binary analysis: Changes in credit-to-GDP ratio with respect to episode type (-1: bust;1: non-costly boom; 2: costly boom) 

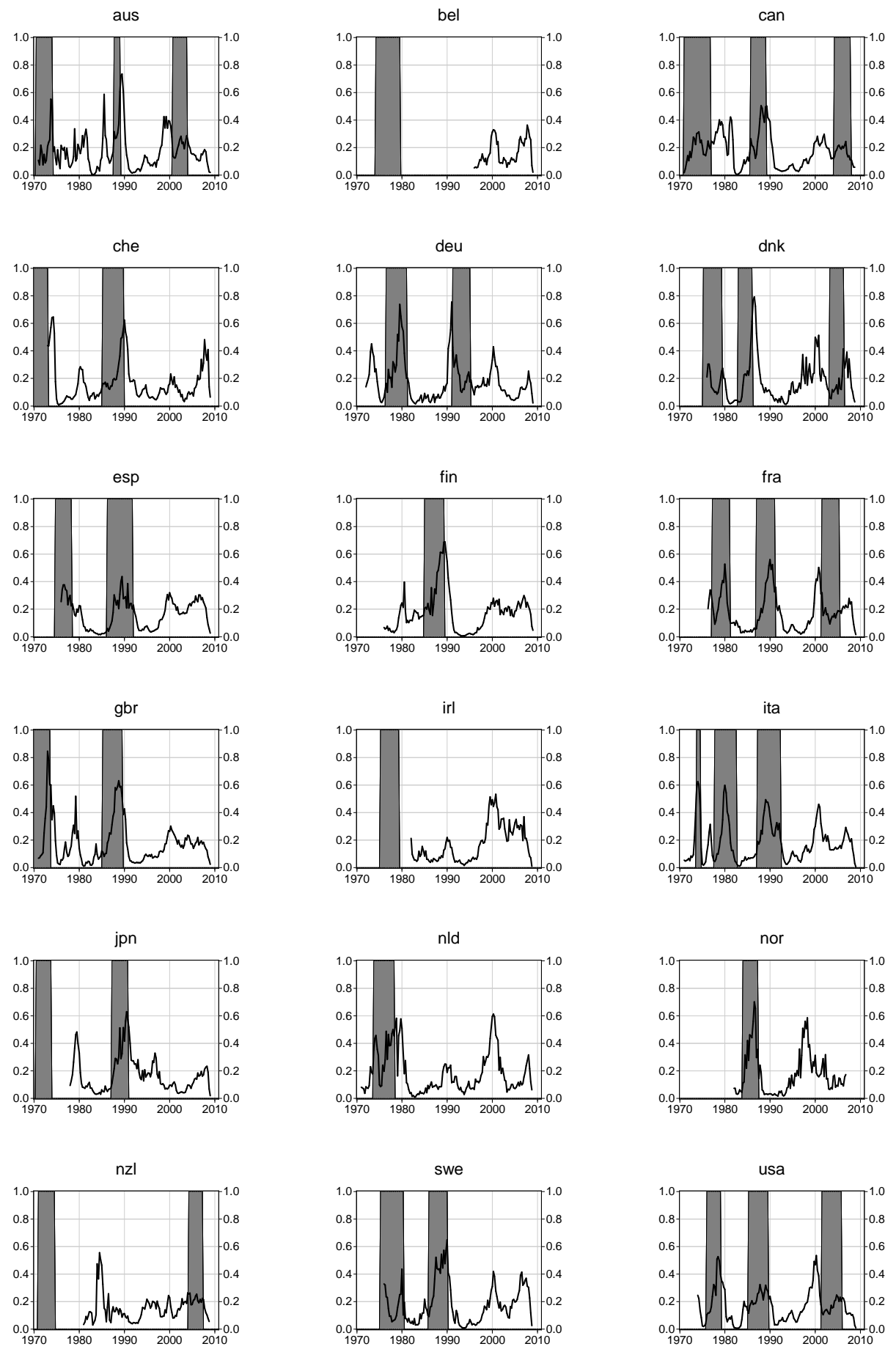

Figure 18: Estimated probability of a housing boom (by country): HP-extended identification methodology 

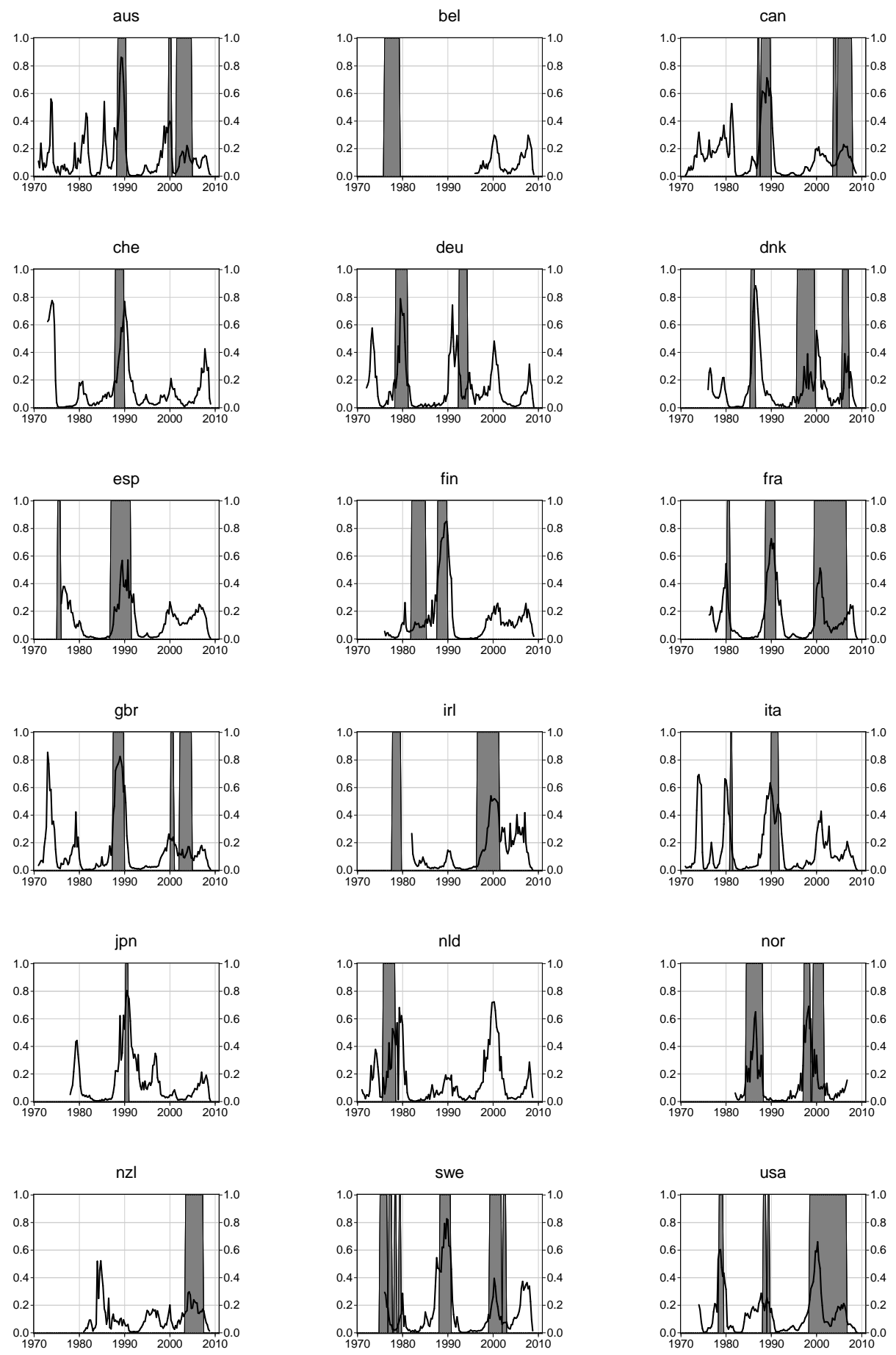

Figure 19: Estimated probability of a housing boom (by country): Recursive-HP identification methodology 

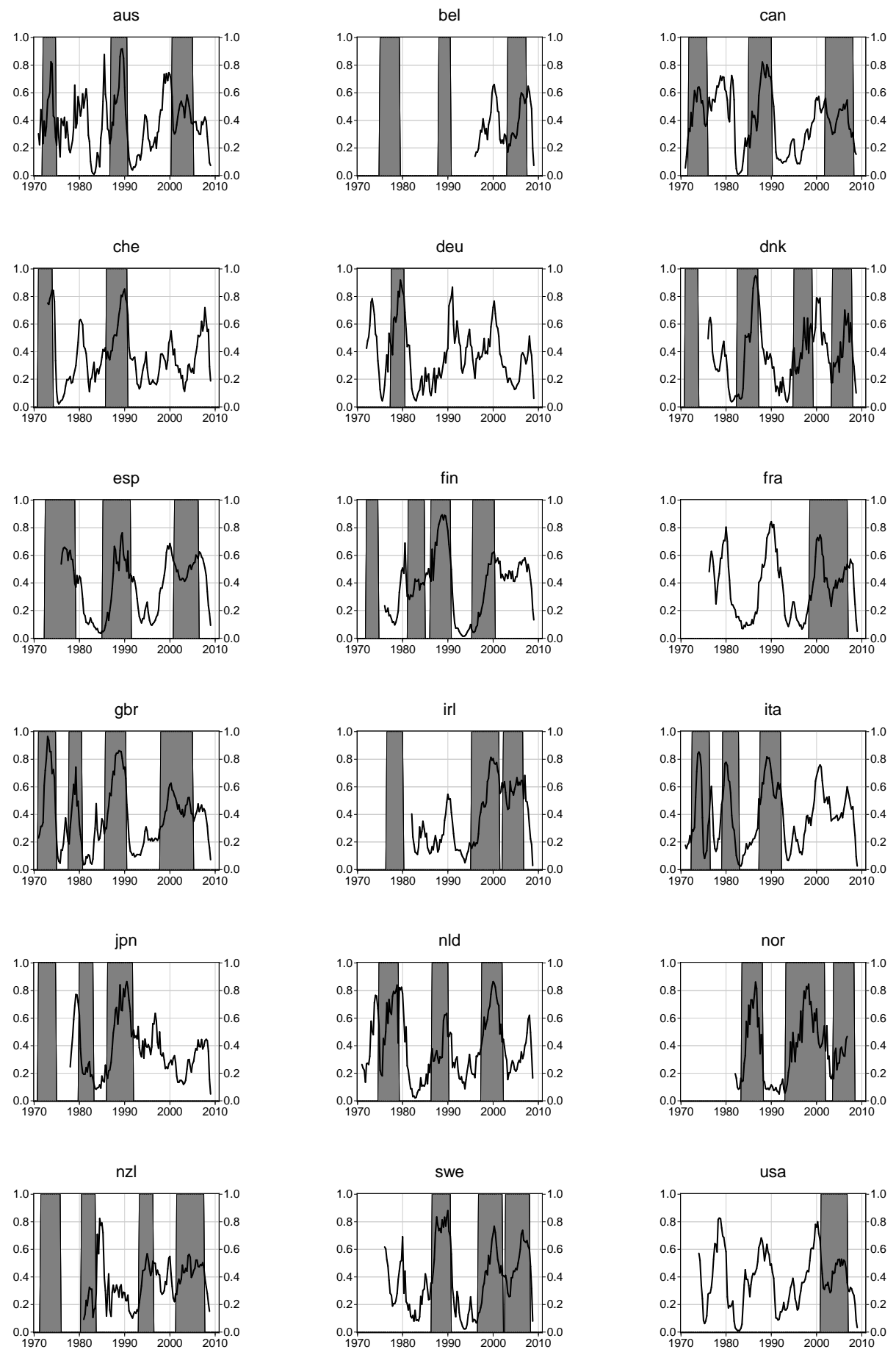

Figure 20: Estimated probability of a housing boom (by country): Moving average identification methodology 

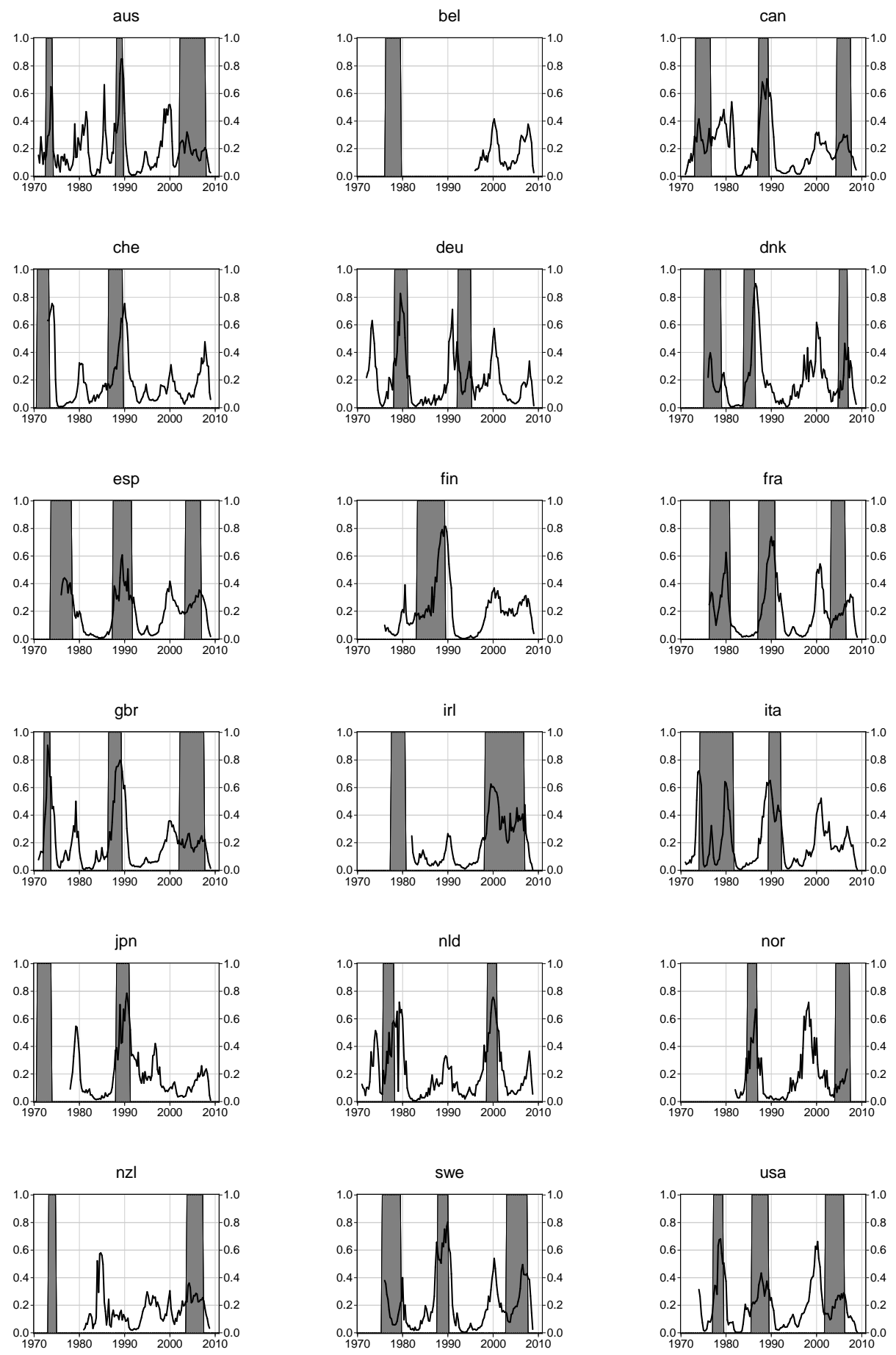

Figure 21: Estimated probability of a housing boom (by country): Band Pass filter identification methodology 

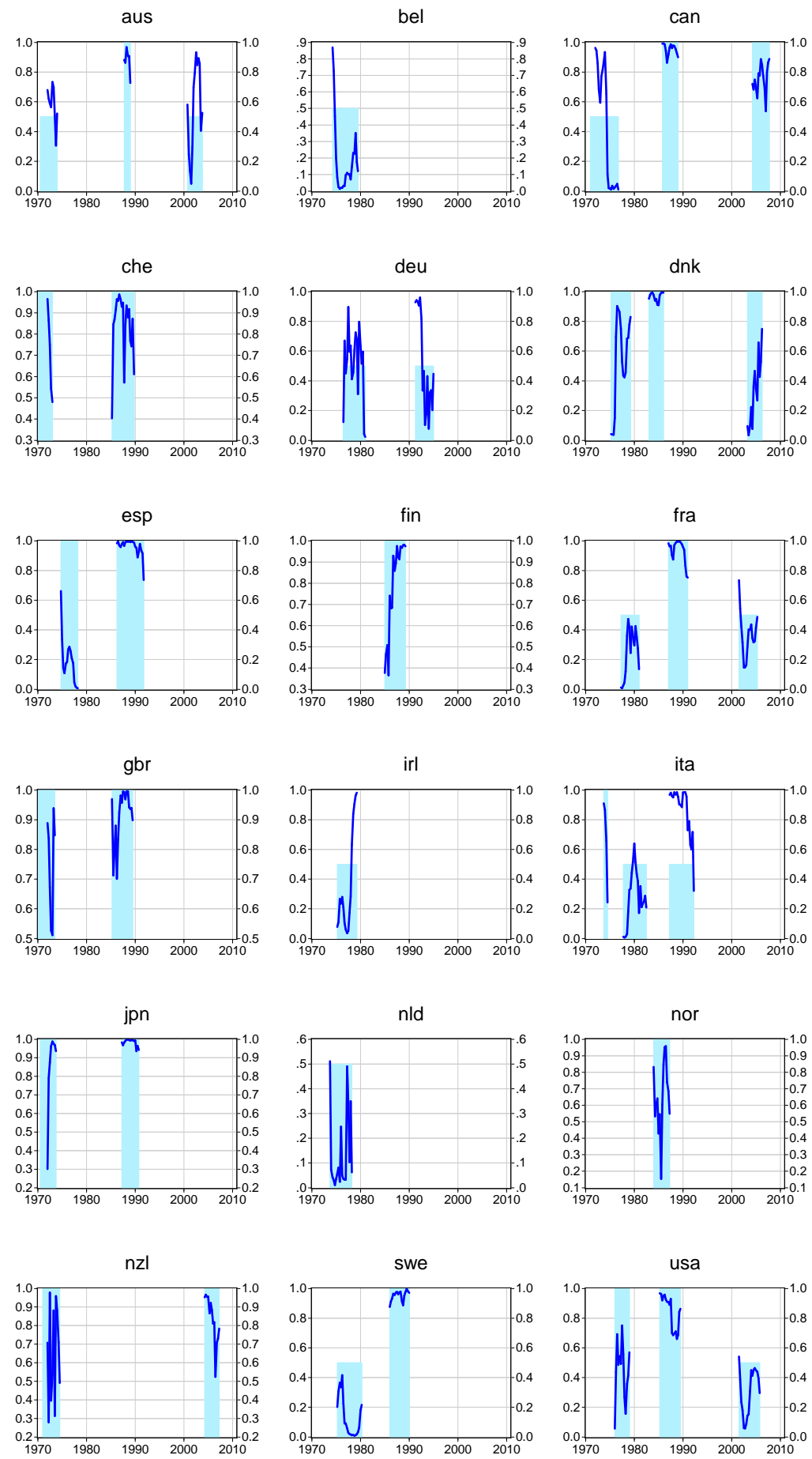

Figure 22: Estimated probability of a costly (vs. low cost or costless) housing boom (by country): HP-extended identification methodology. The larger (respectively the smaller) vertical bars correspond to costly (respectively costless or low-cost) booms. 

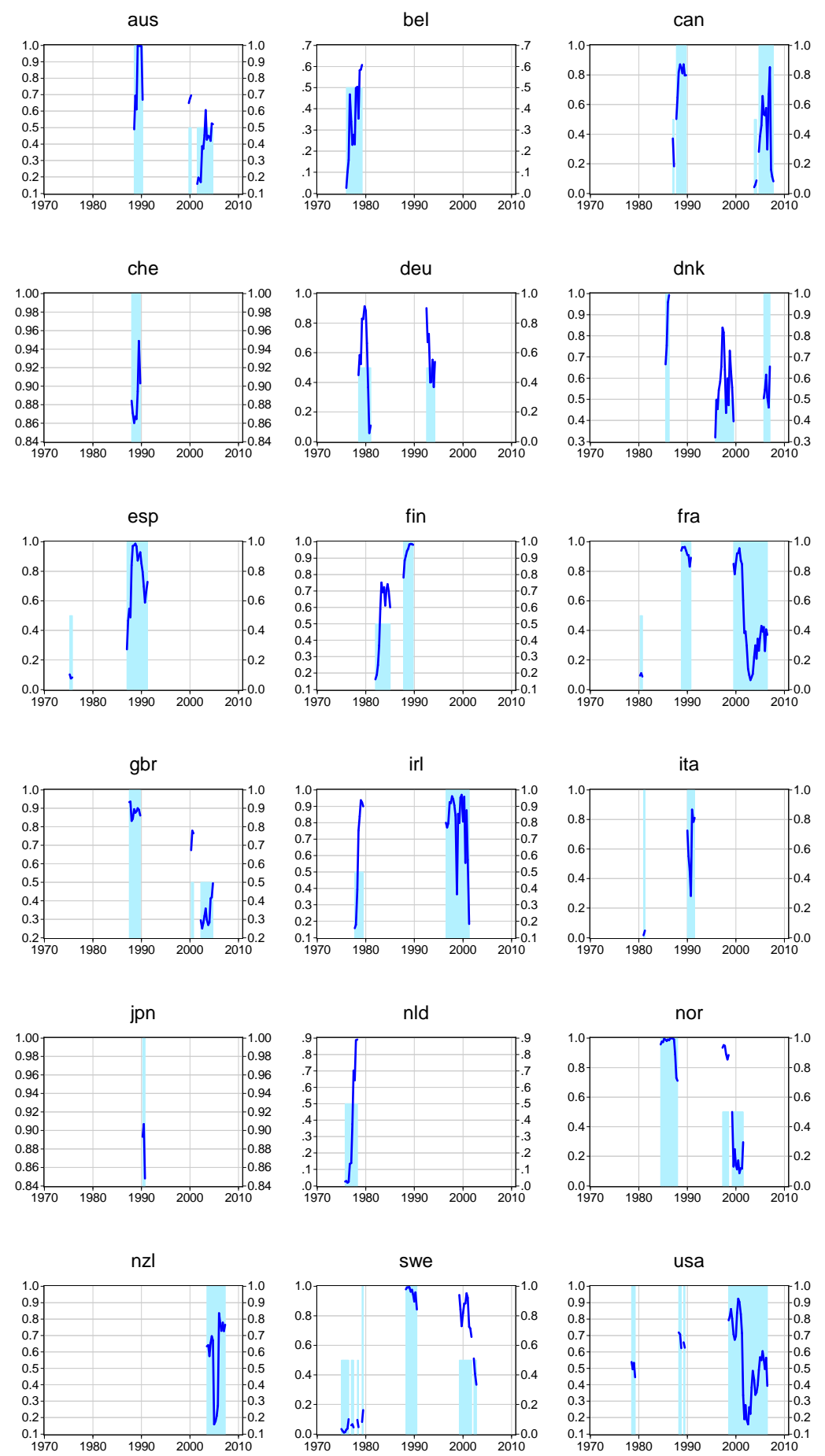

Figure 23: Estimated probability of a costly (vs. low cost or costless) housing boom (by country): Recursive-HP identification methodology. The larger (respectively the smaller) vertical bars correspond to costly (respectively costless or low-cost) booms. 

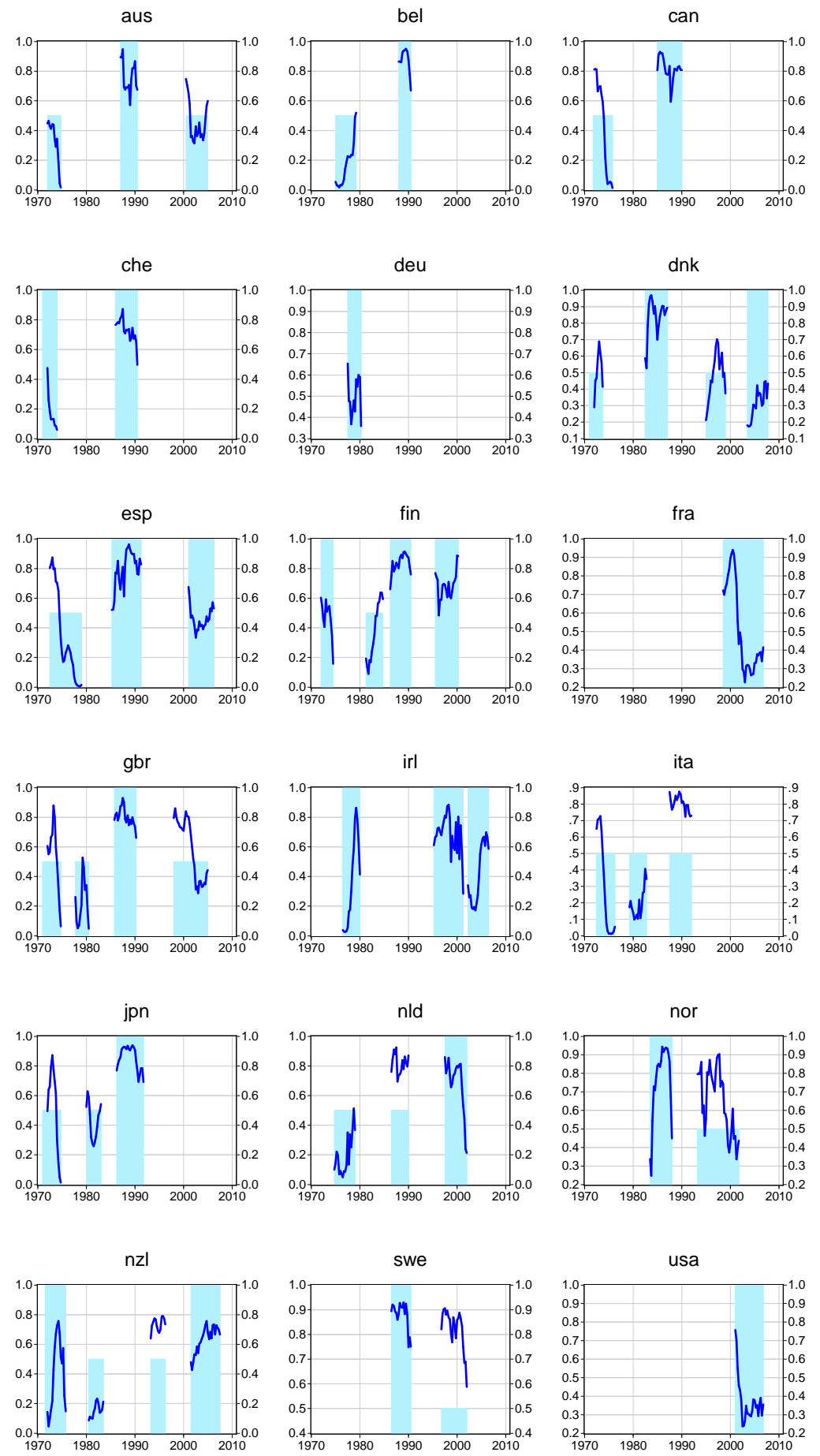

Figure 24: Estimated probability of a costly (vs. low cost or costless) housing boom (by country): Moving average identification methodology. The larger (respectively the smaller) vertical bars correspond to costly (respectively costless or low-cost) booms. 

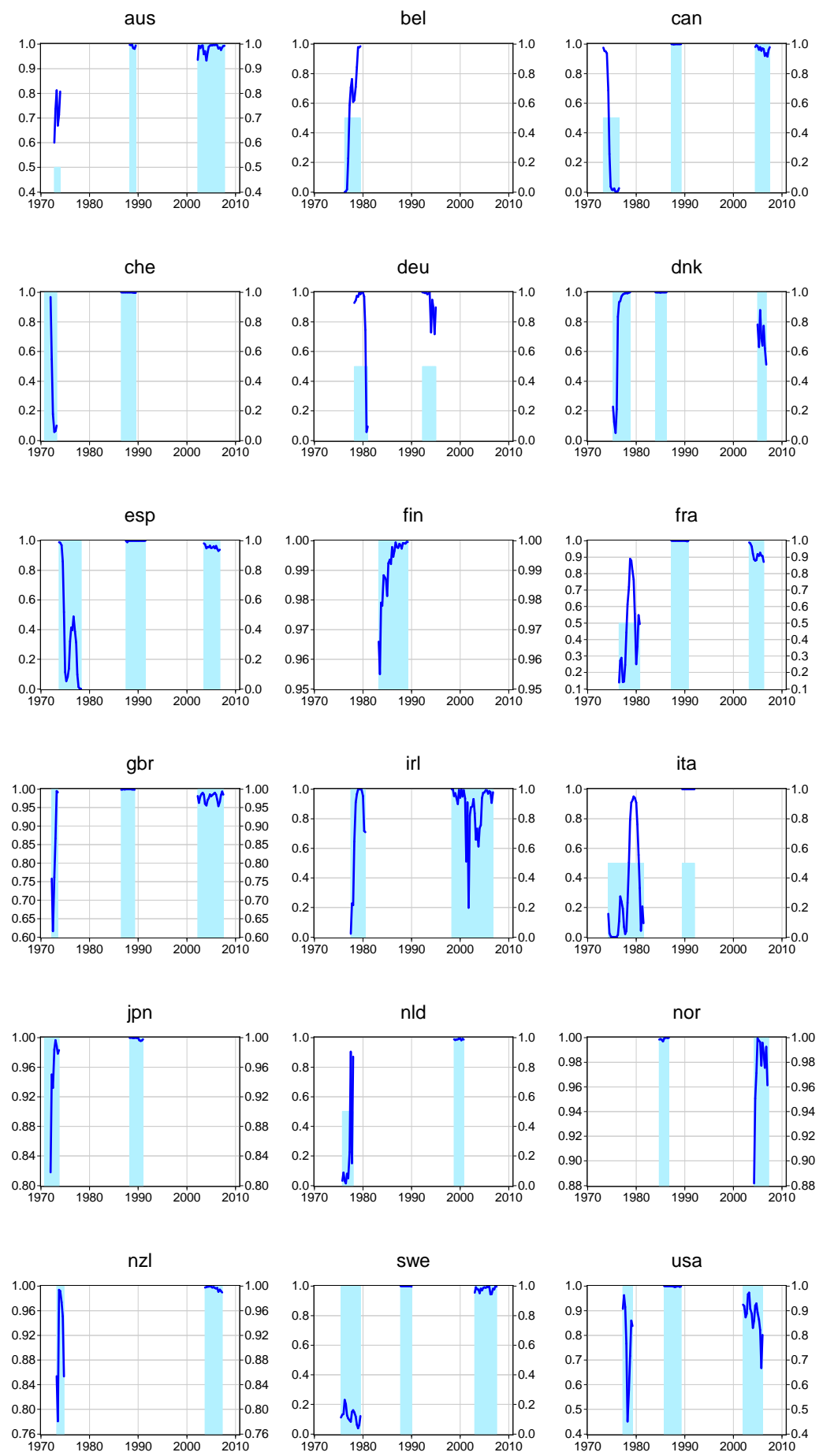

Figure 25: Estimated probability of a costly (vs. low cost or costless) housing boom (by country): Band-Pass filter identification methodology. The larger (respectively the smaller) vertical bars correspond to costly (respectively costless or low-cost) booms. 

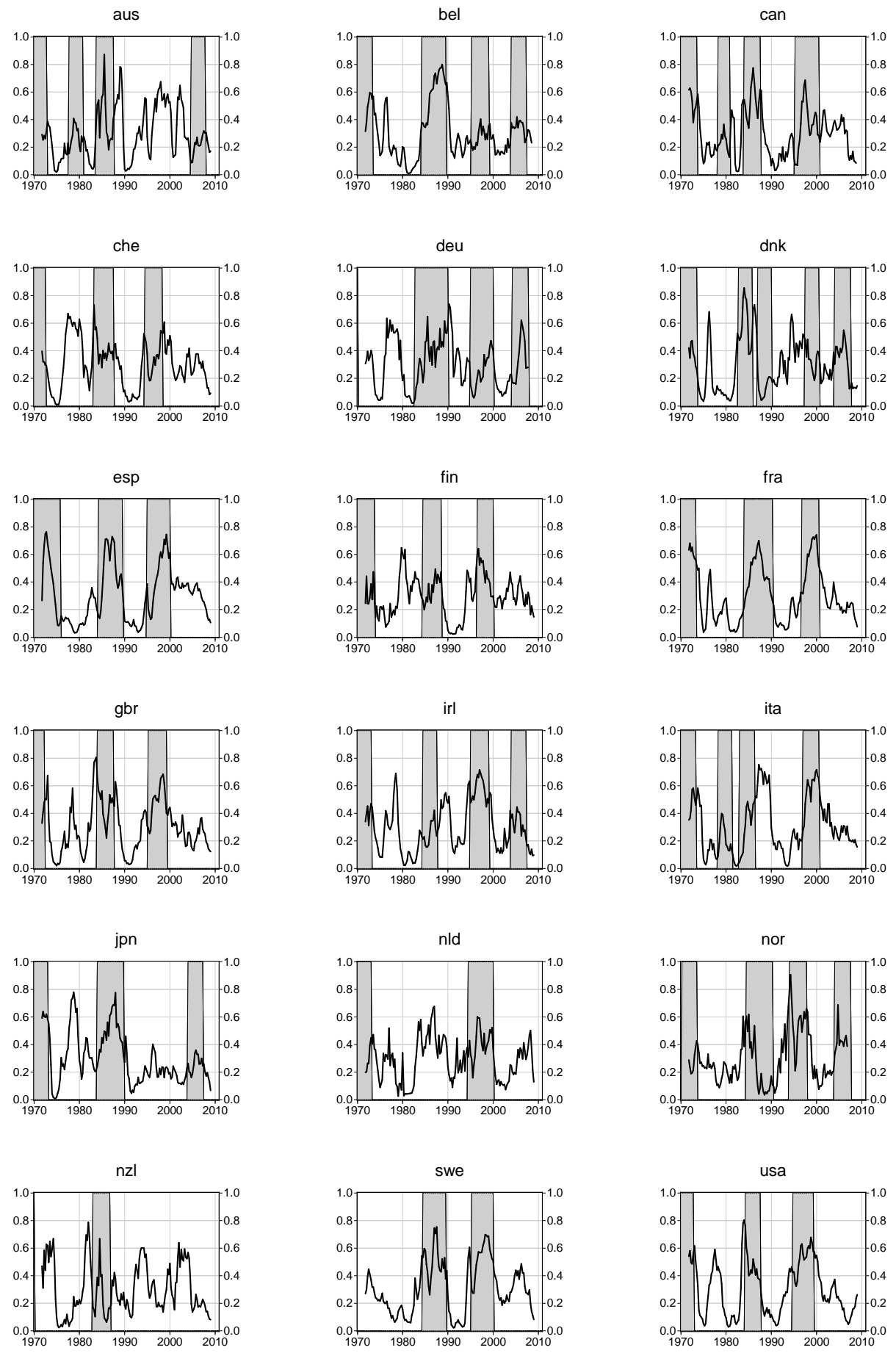

Figure 26: Estimated probability of a stock-price boom (by country): HP-extended identification methodology 

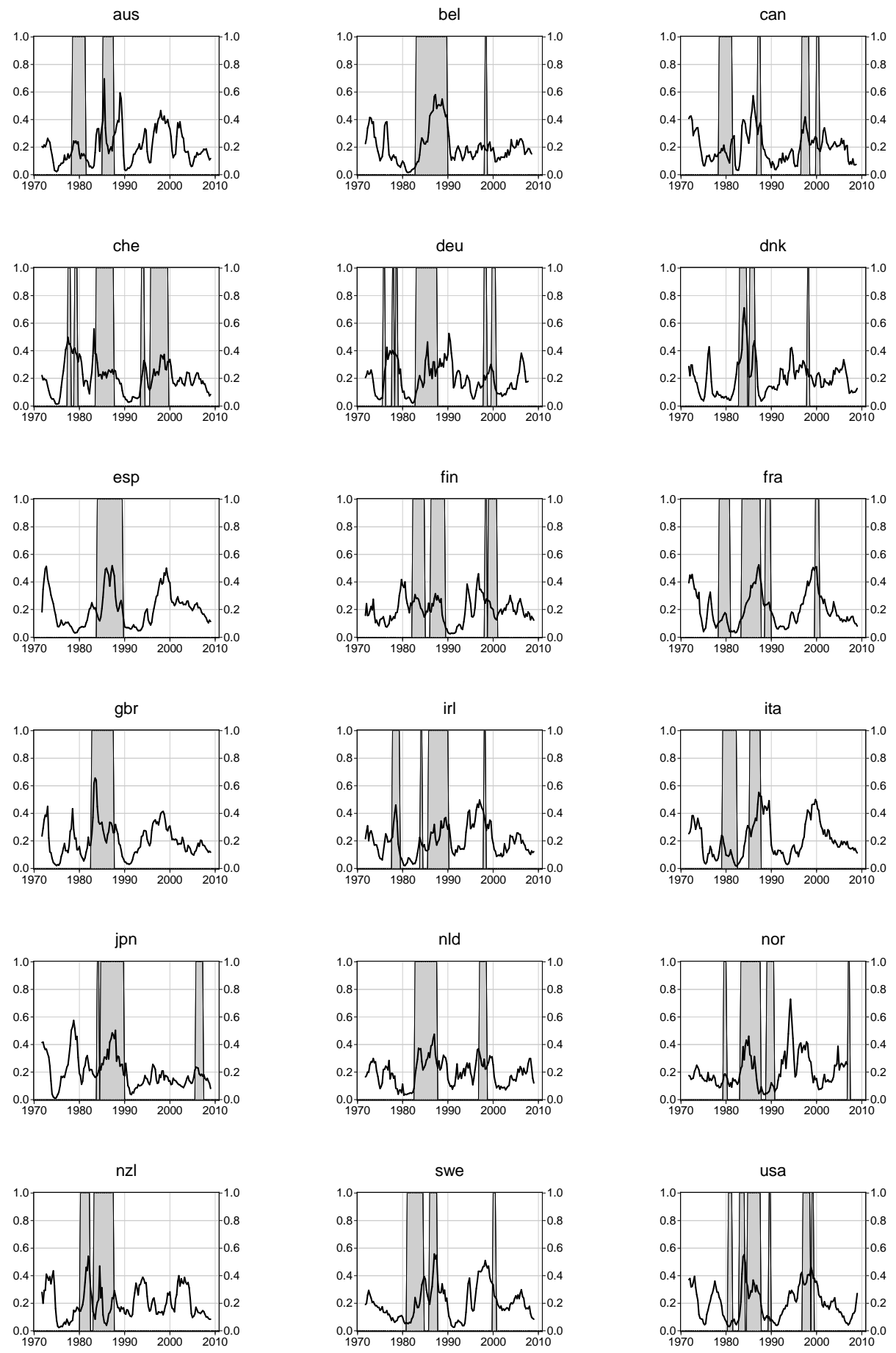

Figure 27: Estimated probability of a stock-price boom (by country): Recursive-HP identification methodology 

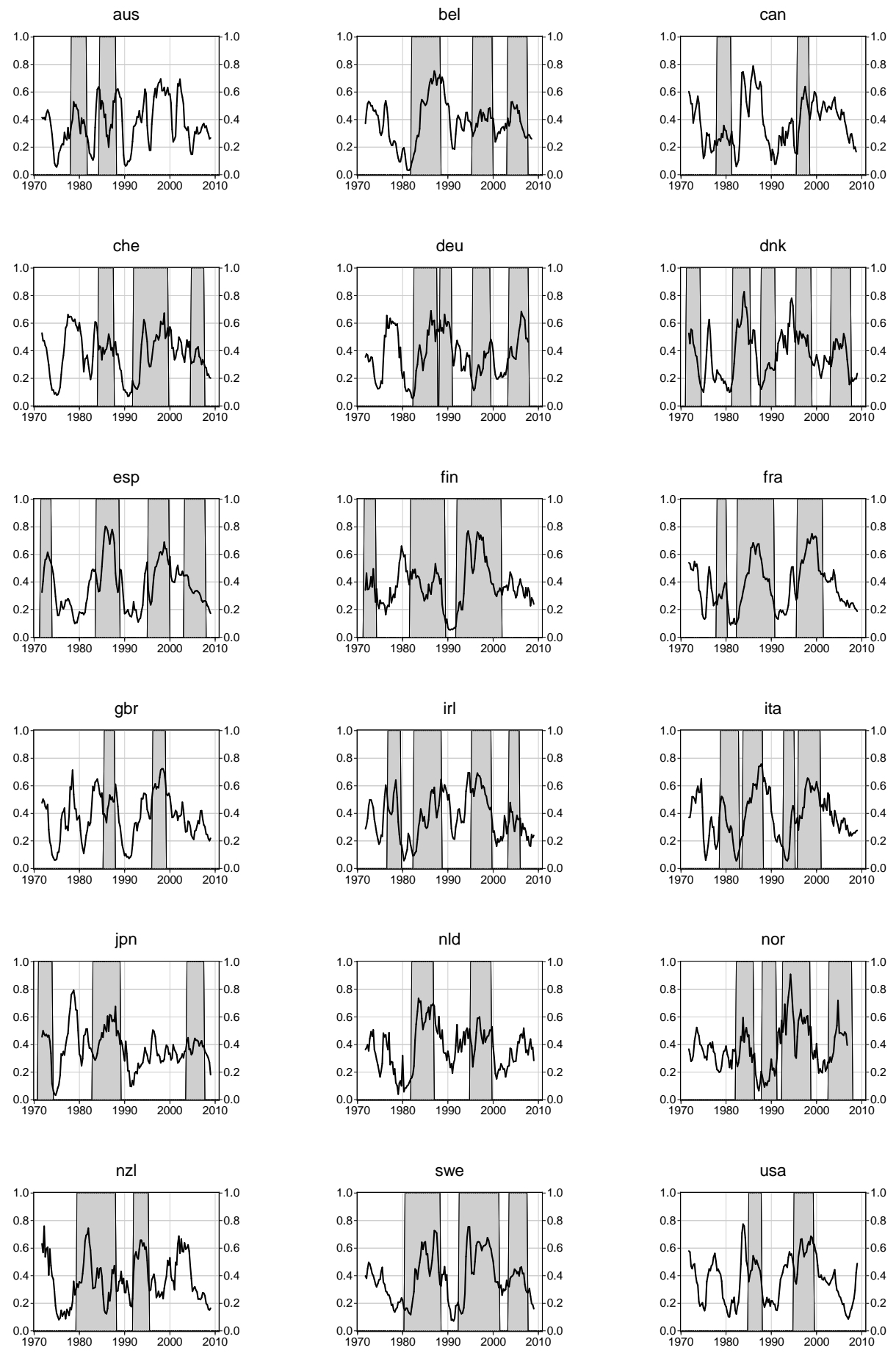

Figure 28: Estimated probability of a stock-price boom (by country): Moving average identification methodology 

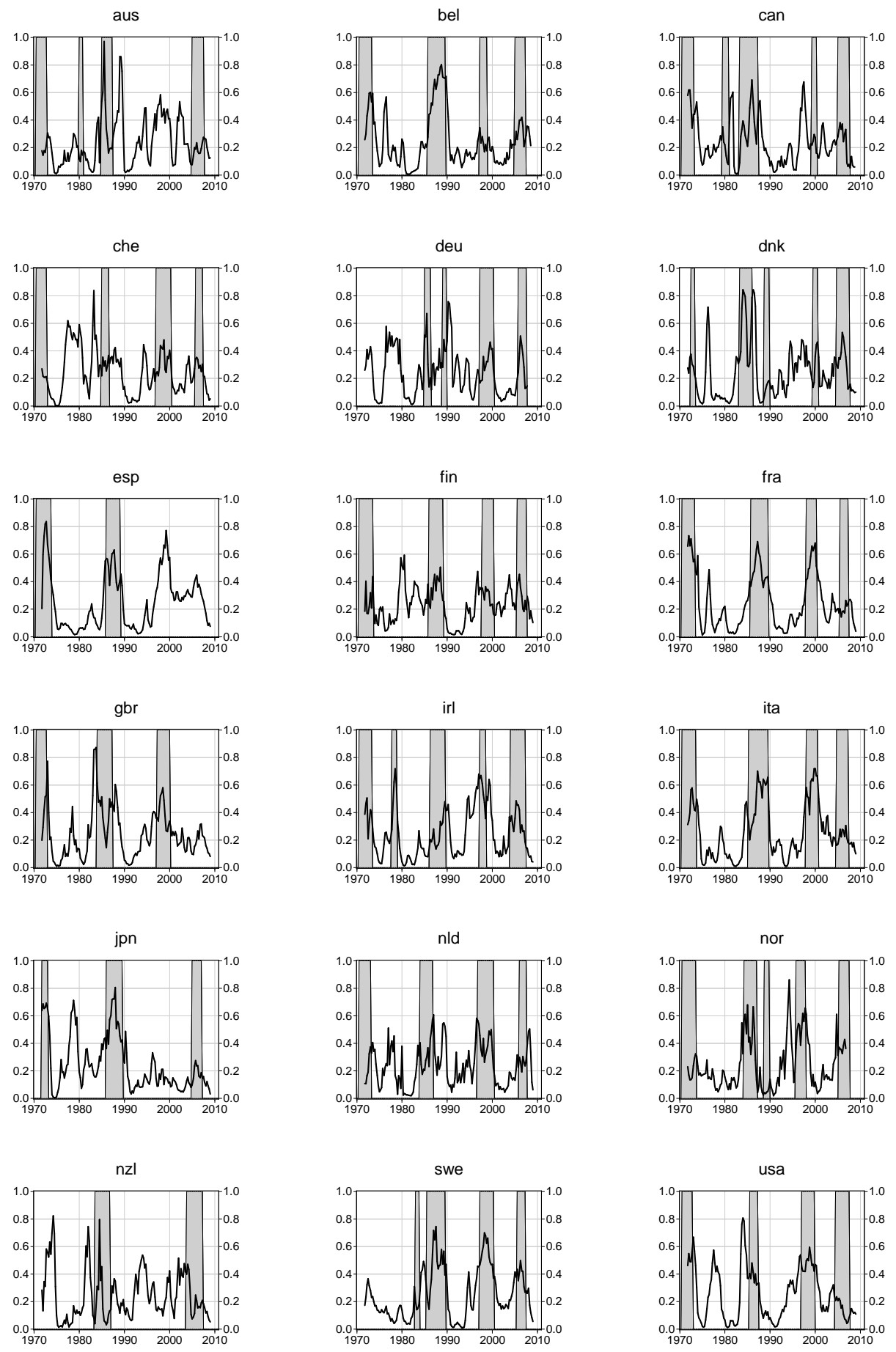

Figure 29: Estimated probability of a stock-price boom (by country): Band Pass filter identification methodology 

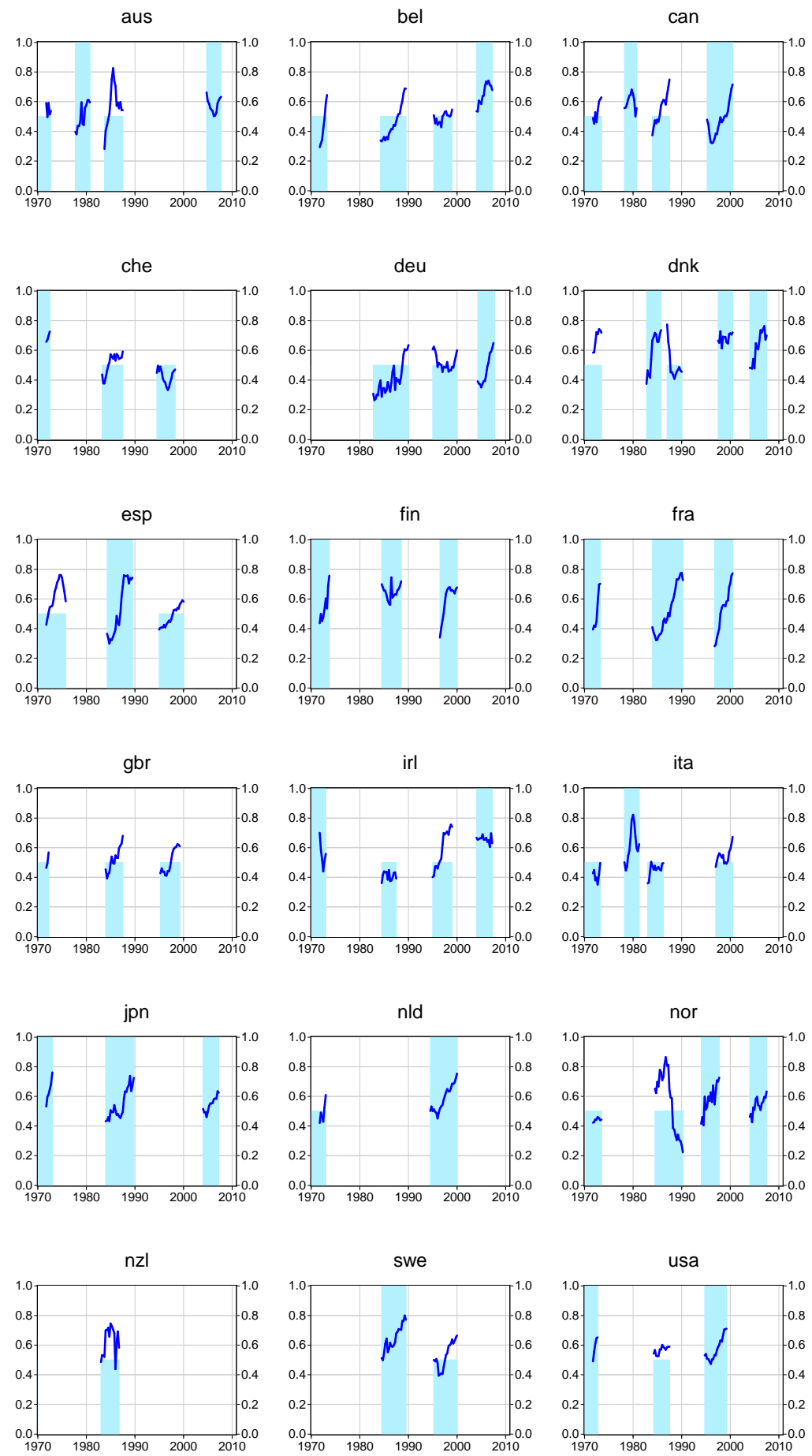

Figure 30: Estimated probability of a costly (vs. low cost or costless) stock-price boom (by country): HP-extended identification methodology. The larger (respectively the smaller) vertical bars correspond to costly (respectively costless or low-cost) booms. 

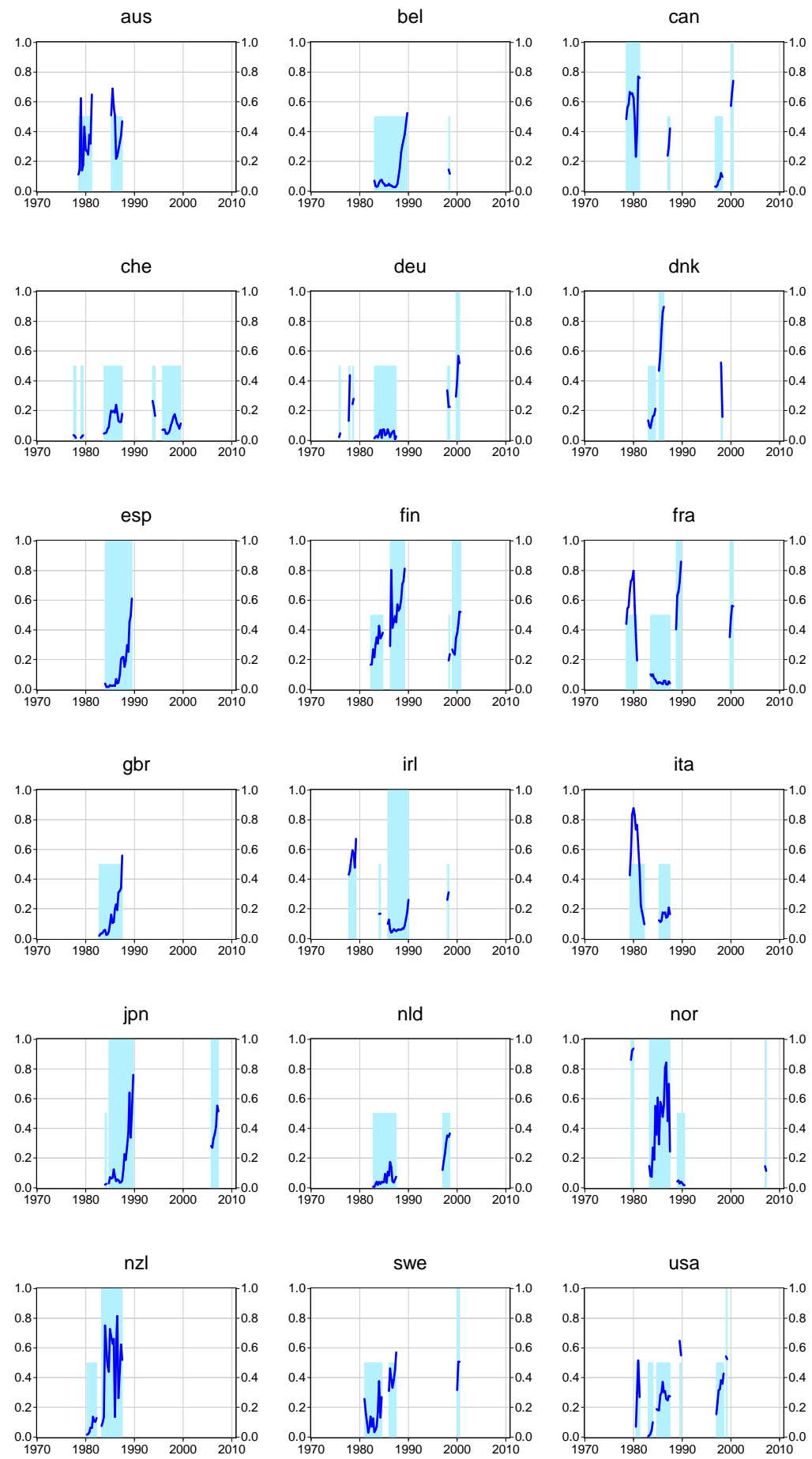

Figure 31: Estimated probability of a costly (vs. low cost or costless) stock-price boom (by country): Recursive-HP identification methodology. The larger (respectively the smaller) vertical bars correspond to costly (respectively costless or low-cost) booms. 

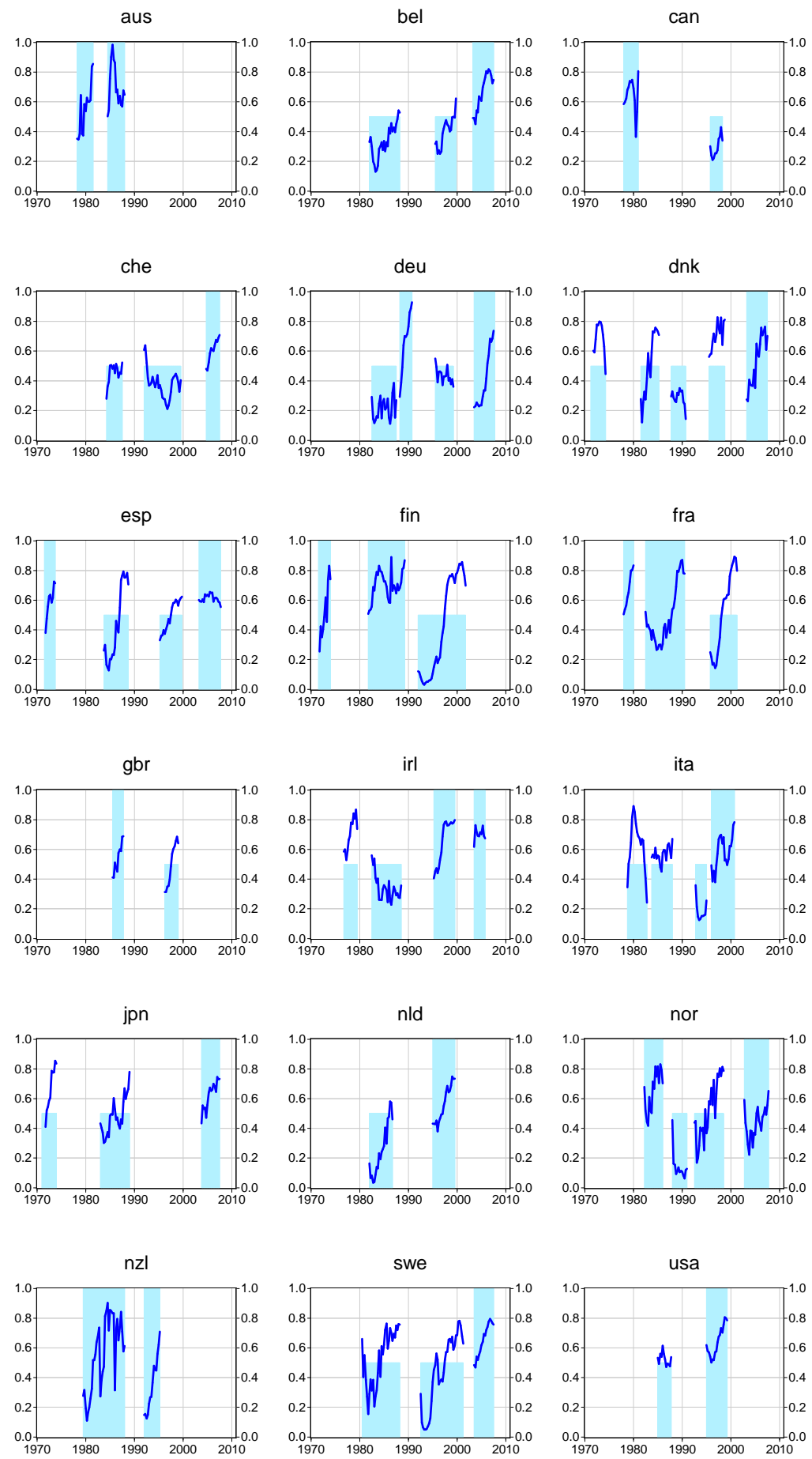

Figure 32: Estimated probability of a costly (vs. low cost or costless) stock-price boom (by country): Moving average identification methodology. The larger (respectively the smaller) vertical bars correspond to costly (respectively costless or low-cost) booms. 

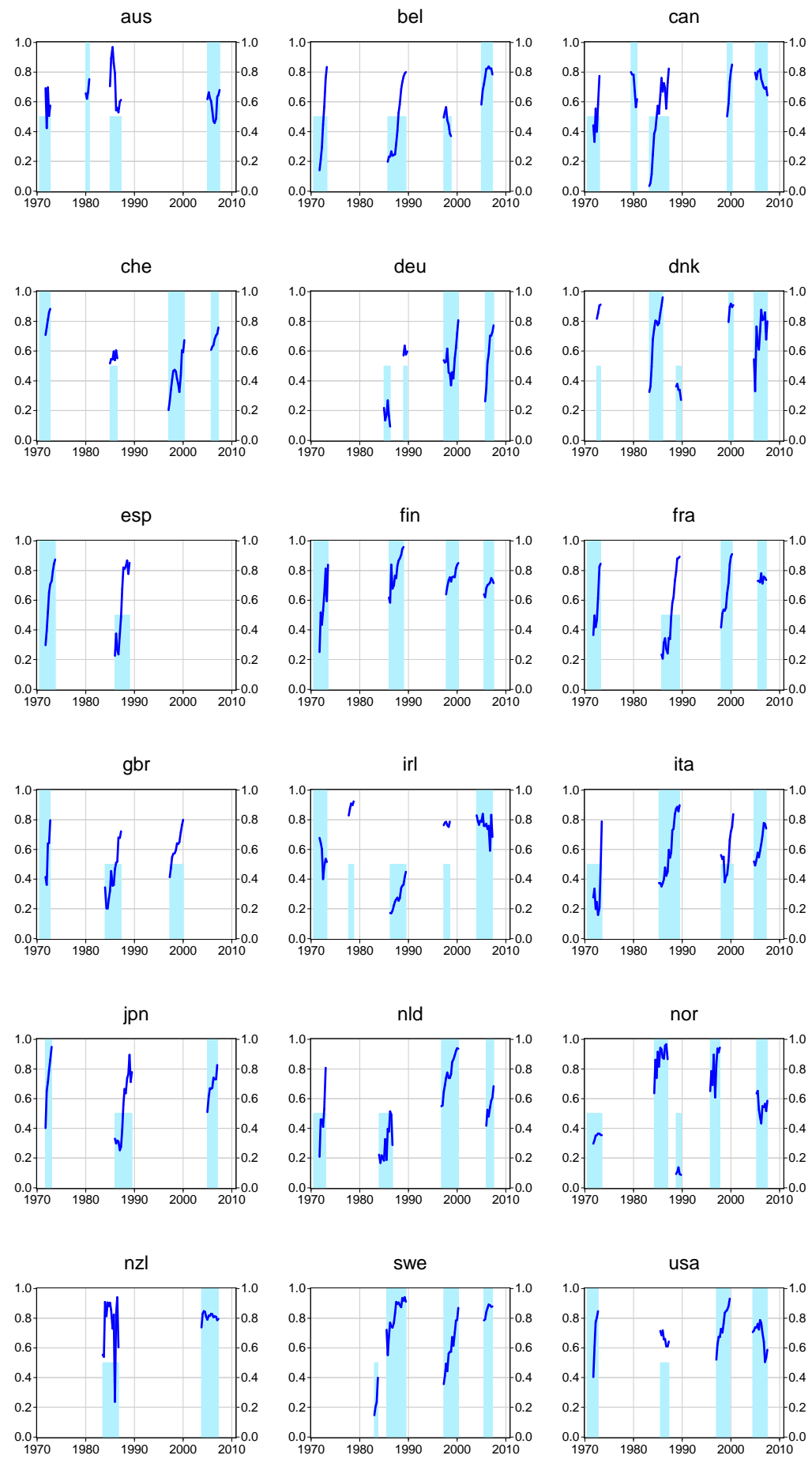

Figure 33: Estimated probability of a costly (vs. low cost or costless) stock-price boom (by country): Band-Pass filter identification methodology. The larger (respectively the smaller) vertical bars correspond to costly (respectively costless or low-cost) booms. 